\title{
Transição da norma ABNT NBR ISO 14001 versão 2004 para versão 2015 e proposta de atualização da matriz de aspectos e impactos ambientais de uma concessionária de rodovias
}

\author{
Luiz Eduardo Pasqualin Machado \\ Instituto Federal do Rio Grande do Sul (IFRS) - Campus Porto Alegre \\ (eduardopasqualin@outlook.com) \\ Magali da Silva Rodrigues \\ Instituto Federal do Rio Grande do Sul (IFRS) - Campus Porto Alegre \\ (magali.rodrigues@poa.ifrs.edu.br)
}

\begin{abstract}
Resumo: Com a crescente preocupação ambiental nas últimas décadas, as organizações passaram a dar maior importância às práticas sustentáveis. Surgem as Normas para os Sistemas de Gestão Ambiental (SGA), estabelecendo requisitos no intuito de prover às organizações uma estrutura para a proteção do meio ambiente. Mais de vinte anos após a primeira publicação, a ISO 14001 chega a sua terceira versão (2015), com o objetivo de se permanecer relevante durante as próximas décadas. A implantação de um SGA tem por premissa a identificação dos aspectos e impactos ambientais, o que representa o processo inicial exigido na implantação da Norma. Nesta edição, essa fase apresenta provavelmente a maior mudança em relação à versão anterior, devido à perspectiva do ciclo de vida. Este trabalho identifica as mudanças oriundas da edição 2015 e atualiza o levantamento de aspectos e impactos ambientais das principais atividades realizadas pela Triunfo Concepa, empresa do ramo de concessão e exploração de rodovias, certificada pela versão 2004 da Norma. Com a inserção de novos critérios para a avaliação dos impactos ambientais e a reconsideração dos aspectos atrelados à operação de uma rodovia, este trabalho pretende servir de apoio para que a organização estudada realize a transição para a última versão.
\end{abstract}

Palavras-chave: ABNT NBR ISO 14001:2015; Aspectos e Impactos Ambientais; Sistema de Gestão Ambiental.

\section{Transition of ISO 14001:2004 to 2015 version and proposal for updating the matrix of environmental aspects and impacts of a highway concessionaire}

\begin{abstract}
Due to the growing environmental concern in the last decades, organizations have given greater importance to sustainable practices. The standards for Environmental Management Systems emerge, establishing requirements in order to provide organizations with a framework for environment protection. More than twenty years after the first publication, ISO 14001 reaches its third version (2015) with the objective of remaining relevant for the next decades. The implementation of an EMS is based on the identification of environmental aspects and impacts which represents the initial process required in the implementation of the standards. In that edition, this phase probably presents the biggest change from the previous version due to the life cycle perspective. This paper identifies the changes arising from the 2015 edition and updates the survey of environmental aspects and impacts of the main activities executed by "Triunfo Concepa", a company in the field of highway concession and exploration, certified by the 2004 version of the standard. With the inclusion of new criteria for the evaluation of environmental impacts and the reconsideration of the aspects related to the operation of a highway, this work intends to serve as a support for the organization under study in the transition to ISO 14001: 2015.
\end{abstract}

Keywords: ISO 14001:2015; Environmental Aspects and Impacts; Environmental Management System. 


\section{INTRODUÇÃO}

A partir da Revolução Industrial, em meados do século XVIII, o homem aumentou exponencialmente a capacidade de alterar as propriedades do seu ambiente. $O$ total de habitantes gerou uma maior demanda por bens e serviços devido ao aumento no volume de produção e, desde então, a degradação ambiental foi intensificada (SEIFFERT, 2010). O capitalismo e a industrialização trouxeram consigo um grande aumento da riqueza e empurraram as fronteiras da humanidade em direção a extremidades que antes seriam inimagináveis (ENGUITA, 1989). O padrão de consumo adotado pelas populações, tornou-se cada vez mais exigente, sofisticado e esbanjador.

$\mathrm{Na}$ década de 1950 ocorreu uma sequência de eventos e acidentes ambientais, que começam a chamar a atenção da sociedade para a crescente degradação da qualidade ambiental e, também, para o fato de que a qualidade de vida e sobrevivência do homem em longo prazo está por ela condicionada (SEIFFERT, 2010). Esse histórico de problemas ambientais demonstra uma maior preocupação com o meio ambiente e o desenvolvimento econômico, tornado-se um tema cada vez mais associado aos debates internacionais, no que se refere ao futuro da humanidade.

Em 1983, foi criada pela ONU a World Commission on Environment and Development (Comissão Mundial sobre Meio Ambiente e Desenvolvimento - CMMAD), também conhecida como 'The Brundtland Comission' (Comissão Brundtland), por ser presidida pela primeira-ministra norueguesa Gro Harlem Brundtland. Em 1987 houve a aprovação e divulgação pela ONU do Relatório 'Our Common Future' (Nosso Futuro Comum), desenvolvido pela Comissão Brundtland (ALBERTON, 2003). Neste relatório é estabelecido o conceito do "Desenvolvimento Sustentável", estabelecendo que o atendimento às necessidades do presente não deve comprometer a capacidade de as futuras gerações atenderem às suas (BRUNTLAND, 1987).

A sociedade adquiriu uma consciência ecológica a partir dos anos 1990, que obrigou a adoção de novas posturas organizacionais. Em função disso foram adotadas novas práticas administrativas, agora pautadas no desenvolvimento sustentável. Isso trouxe como implicações para as organizações uma série de transformações, pois 
agora é preciso aumentar a lucratividade e reduzir gastos, mas com produto/serviço de qualidade e ecologicamente correto (NETO, De SOUZA e SHIGUNOV, 2009).

A Conferência das Nações Unidas sobre Meio Ambiente (CNUMAD ou United Nations Conference on Environment and Development - UNCED) foi o acontecimento mais marcante do início da década de 1990 e, até hoje, a maior das respostas à crise ambiental global enfrentada pela humanidade. A Conferência das Nações Unidas sobre Meio Ambiente e Desenvolvimento, também conhecida como ECO-92, RIO-92 ou ainda 'The Earth Summit' (A Cúpula da Terra), ocorreu na cidade do Rio de Janeiro, Brasil, em junho de 1992 (ALBERTON, 2003). A gestão ambiental, que era uma preocupação governamental, passa a fazer parte também do meio empresarial.

Segundo Barbieri (2004, apud NETO, DE SOUZA E SHIGUNOV 2009), a gestão ambiental pode ser definida como: "as diretrizes e as atividades administrativas e operacionais, tais como: planejamento, direção, controle, alocação de recursos e outras realizadas com objetivo de obter efeitos positivos sobre o meio ambiente, quer reduzindo ou eliminando danos ou problemas causados pelas ações humanas, quer evitando que elas surjam". A RIO-92 teve como objetivo discutir e sugerir soluções potenciais para temas ambientais globais. Dois importantes resultados desta conferência foram a Agenda 21 e as Normas da série ISO 14000. Ambos são instrumentos valiosíssimos para a gestão ambiental (SEIFFERT, 2006).

A ISO - International Standardization Organization foi fundada em 1947 para promover o desenvolvimento de padrões internacionais. É uma federação mundial, não governamental, com sede em Genebra, na Suíça. A ISO possui mais de 110 países participantes, entre eles o Brasil, cuja representante é a ABNT - Associação Brasileira de Normas Técnicas (ALBERTON, 2003). A ISO criou o SAGE (Strategic Advisory Group on Environment), com o objetivo de propor as ações necessárias para um enfoque sistêmico de normatização ambiental e certificação. Os trabalhos do SAGE resultaram na criação do Comitê Técnico 207 - Gestão Ambiental, cujos esforços se refletem na elaboração do Sistema ISO 14000 (NAHUZ, 1995).

A década de 1990 colocou em evidência os problemas relacionados ao clima e como isso poderia comprometer a sobrevivência dos ecossistemas. Houve grande impulso com relação à consciência ambiental na maioria dos países, aceitando-se 
pagar um preço da qualidade de vida e mantendo-se limpo o ambiente. As empresas passaram a dar importância à racionalização do uso de energia e de matérias-primas essenciais, além de maior empenho e estímulos à reciclagem e reutilização, evitando desperdícios (SEIFFERT, 2010).

Com isso, as indústrias sentiram a necessidade de dispor de Normas para os Sistemas de Gestão Ambiental, o que resultou na elaboração e lançamento da BS 7750 pela British Standards Institution, da Grã-Bretanha, em 1992 (NAHUZ, 1995). A Figura 1 ilustra a evolução da Norma ISO 14001.

Figura 1 - Evolução da Norma ISO 14001

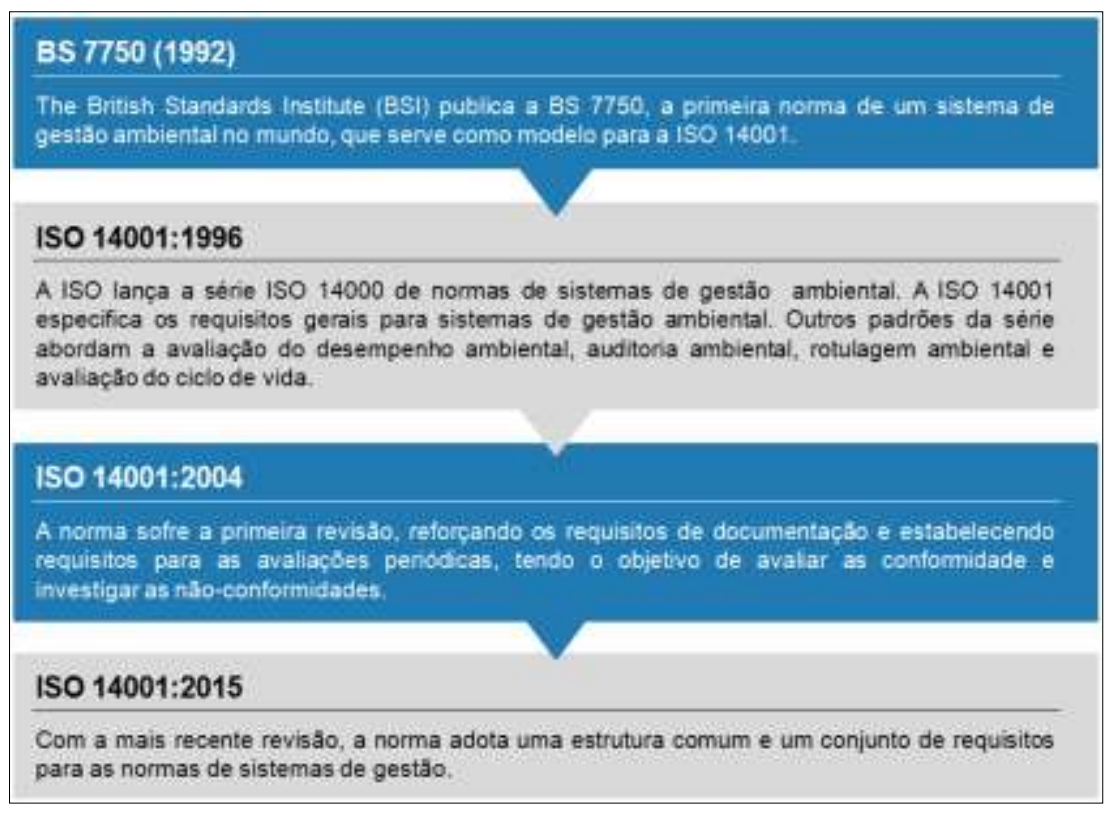

Fonte: Adaptado de TÜV SÜD, 2015.

A ISO 14001 teve como padrão a Norma Britânica BS 7750, sendo a única Norma ambiental que pode conceder certificado às organizações. Ela foi emitida experimentalmente em 1992 e reeditada em 2 de janeiro de 1994, porém, só veio a ser implantada pelas empresas em 1996 (ALBERTON, 2003).

A Figura 2 apresenta a evolução anual das certificações ISO 14001 no mundo. 
Figura 2 - Evolução anual das certificações ISO 14001.

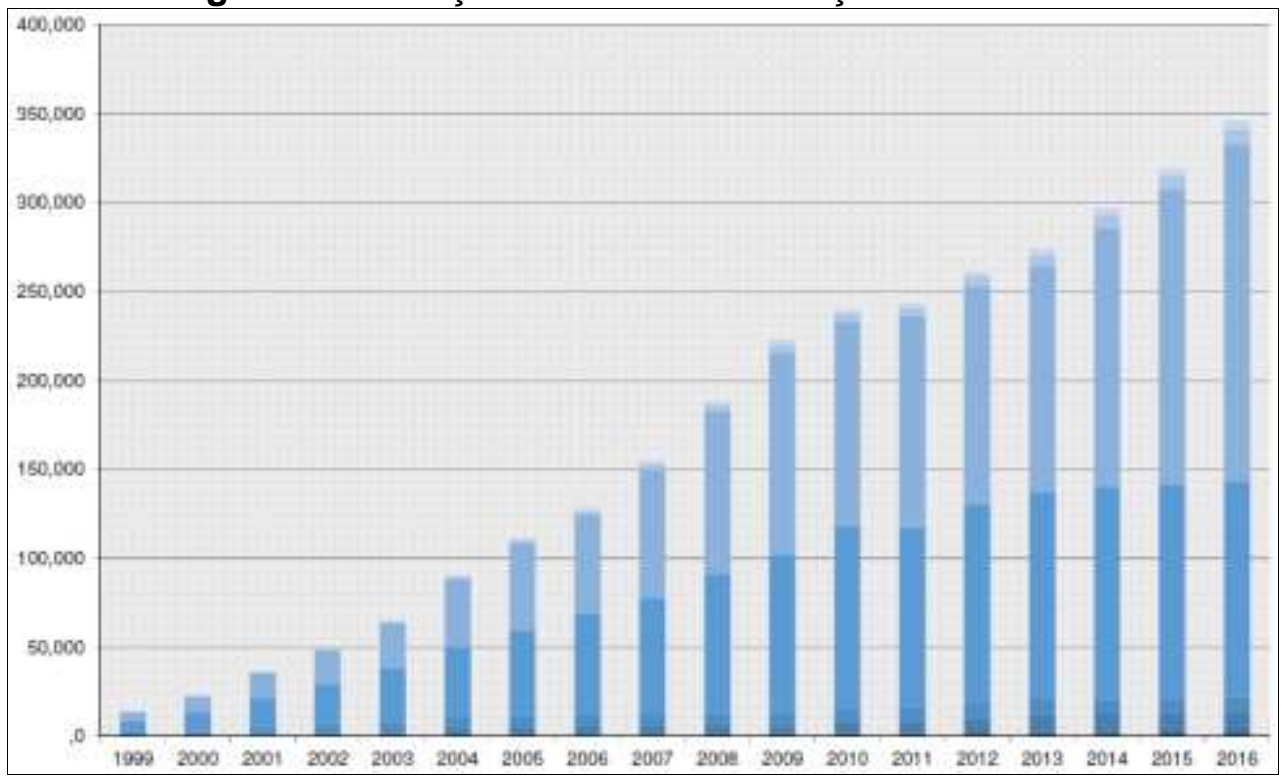

Fonte: ISO, 2016a.

Ao analisar o gráfico, é possível observar que existe uma tendência de aumento anual constante no número de organizações certificadas. Segundo o levantamento mais recente, em 2016 a ISO 14001 chegou ao número de 346.147 certificações válidas mundialmente, sendo a segunda Norma mais utilizada no mundo, ficando atrás da ISO 9001, de Sistemas de Gestão da Qualidade.

O Sistema de Gestão Ambiental (SGA) é um conjunto de elementos interrelacionados ou interativos de uma organização para estabelecer políticas, objetivos e processos, com o intuito de prover às organizações uma estrutura para a proteção do meio ambiente e possibilitar uma resposta às mudanças das condições ambientais em equilíbrio com as necessidades socioeconômicas (ABNT, 2015).

Os requisitos do sistema baseiam-se no modelo PDCA (Plan-Do-Check-Act), conforme a Figura 3. O conceito consiste em planejar (Plan), fazer (Do), verificar (Check) e agir (Act), formando o ciclo da melhoria contínua, sendo um ponto chave para atingir os resultados pretendidos do SGA (ABNT, 2015). 
Figura 3 - Modelo PDCA.

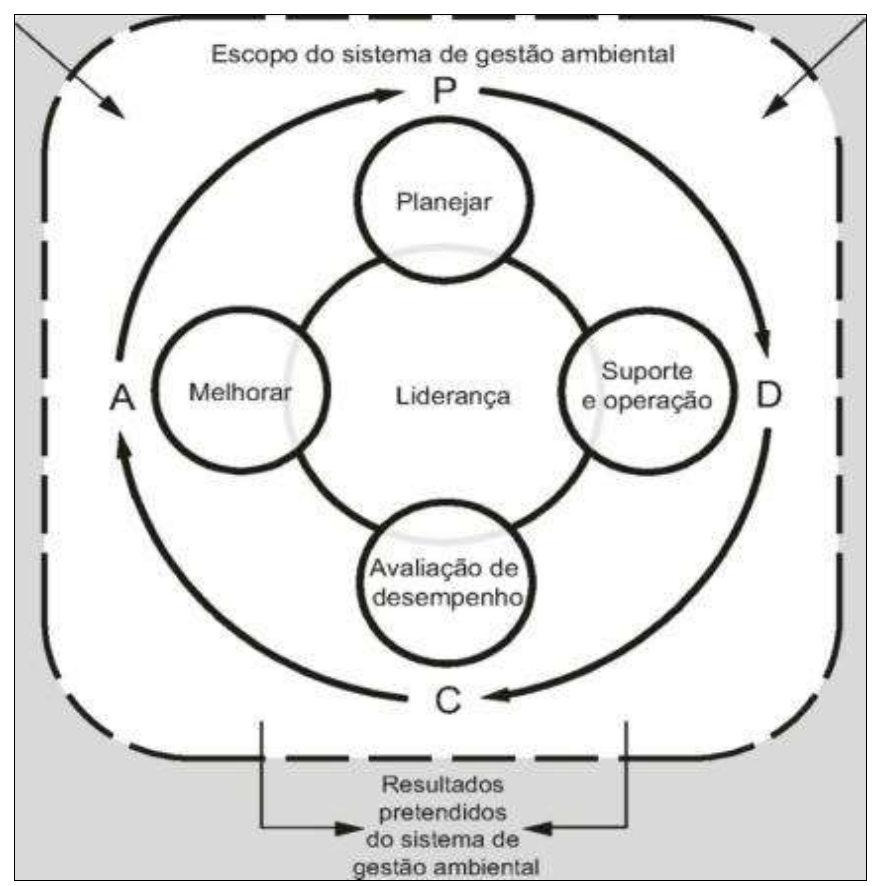

Fonte: ABNT, 2015.

Quando a organização planeja fazer uma mudança na produção ou em um processo, o ciclo PDCA visa a melhoria (planejar), implementação da mudança (fazer), avaliação dos resultados da mudança (checar) e, por fim, institucionalizar a mudança (agir) (KITAZAWA e SARKIS, 2000, p. 229 apud BLACKESTAM e OLOFSSON, 2013).

A adoção de um SGA envolve altos investimentos, que são necessários para a documentação, o treinamento de pessoal e auditorias. Também exige tempo, esforço e outros recursos ao longo do processo. Por isso, a certificação deve ser objeto de um planejamento financeiro minucioso por parte da empresa (ALBERTON, 2003).

Em 2010, o Grupo de Estudos sobre os Desafios Futuros dos Sistemas de Gestão Ambiental publicou um relatório detalhando onze assuntos relevantes para os futuros sistemas de gestão ambiental:

1.SGA como parte da sustentabilidade e responsabilidade social;

2. SGA e (melhoria de) desempenho ambiental;

3. SGA e conformidade com requisitos legais e outros requisitos externos;

4. SGA e gestão empresarial global (estratégica);

5. SGA e avaliação de conformidade; 
6. SGA e a aceitação em pequenas organizações;

7. SGA e impactos ambientais na cadeia de valor e fornecimento;

8. SGA e o envolvimento das partes interessadas;

9. SGA e sistemas paralelos ou sub-sistemas (Gases de Efeito Estufa, energia);

10. SGA e comunicação externa (incluindo informações sobre o produto);

11. Posicionamento do SGA nas agendas políticas nacionais e internacionais.

A partir destes temas, emergiu um conjunto de recomendações, que acarretou na revisão da ISO 14001. Em 2011, foi elaborado um estudo (ISO / TC 207 / SC 1 N 845) para esta revisão, baseado nos princípios de relevância de mercado, compatibilidade, facilidade de uso, cobertura de tópicos, flexibilidade, base tecnicamente sólida, de fácil compreensão, livre comércio, aplicabilidade da conformidade e exclusões (ISO, 2018).

O mandato de revisão da ISO 14001: 2015 (datado de 2012-01-23) estipulou que ela deve ser baseada nos requisitos e diretrizes de aplicação da ISO relacionados à Estrutura de Alto Nível (HLS - High Level Structure). Trata-se de uma nova estrutura comum para todas as Normas de Sistema de Gestão ISO, que incorporam textos centrais idênticos e termos comuns com definições básicas (ISO, 2018).

A Norma está em conformidade com os requisitos da ISO para as Normas de Sistema de Gestão Ambiental, basendo-se na ISO 14004, que provê orientações para o estabelecimento, implementação, manutenção e melhoria de um SGA. A Norma estabelece dez requisitos, conforme a Figura 4. Os primeiros três fazem uma abordagem mais teórica à Norma. Os requisitos de forma especifica iniciam no requisito 4 e terminam no requisito 10. A Figura 4 também expõe como a Norma é estruturada com os novos requisitos e faz uma breve relação com a Norma anterior, a ISO 14001:2004. 
Figura 4 - Estrutura da ISO 14001:2015.

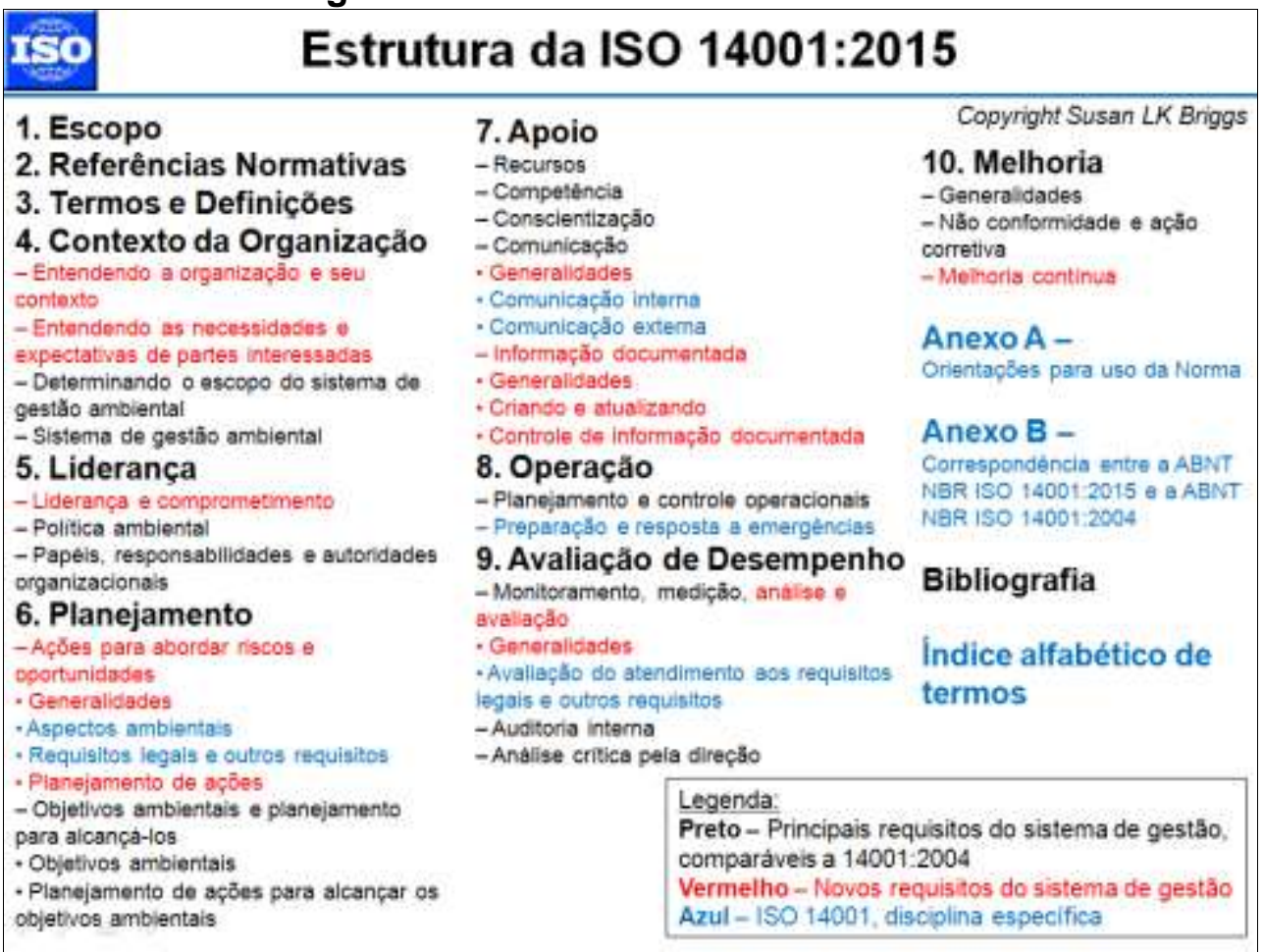

Fonte: Adaptado de Briggs, 2015.

O requisito 6.1.2 "Aspectos Ambientais" determina que a organização deve identificar os aspectos ambientais de suas atividades, produtos e serviços, dentro do escopo definido de seu SGA, quais ela possa controlar e aqueles que ela possa influenciar, e seus impactos ambientais associados, considerando uma perspectiva de Ciclo de Vida - CV (ABNT, 2015).

Ao determinar os aspectos ambientais, a organização deve levar em consideração:

a) mudanças, incluindo desenvolvimentos planejados ou novos, e atividades, produtos e serviços novos ou modificados;

b) condições anormais e situações de emergência razoavelmente previsíveis.

Convém que sejam considerados aspectos ambientais, tais como: projeto e desenvolvimento de suas instalações; processos, produtos e serviços; aquisição de matérias-primas; processos operacionais ou de fabricação, incluindo armazenamento; operação e manutenção de instalações, recursos organizacionais e infraestrutura; 
desempenho ambiental e práticas de provedores externos; transporte de produtos e prestação de serviços, incluindo a embalagem; armazenamento, uso e pós-uso dos produtos e gestão de rejeitos, incluindo a reutilização, recuperação, reciclagem e disposição. Os aspectos ambientais identificados como significativos podem resultar em riscos e oportunidades para o SGA (ABNT, 2015).

Determinar os aspectos e impactos ambientais faz parte de um processo contínuo, o que melhora o entendimento da organização na relação com meio ambiente e contribui para a melhoria contínua do desempenho ambiental. A partir do conhecimento dos aspectos ambientais significativos que deverão ser desenvolvidos os objetivos ambientais, treinamentos, comunicações, controles operacionais, processos de monitoramento e a política ambiental da organização (ISO, 2016b). A adequada implementação deste subsistema é particularmente crítica para a implantação do SGA, porque determinará a sua abragência e robustez (SEIFFERT, 2006).

Pelo exposto, este trabalho se propõe a atualizar o levantamento dos aspectos ambientais e impactos ambientais das principais atividades realizadas pela empresa Triunfo Concepa, que atua no ramo de concessão e exploração de rodovias no estado do Rio Grande do Sul, empresa certificada pela Norma ABNT NBR ISO 14001:2004.

Considerando a importância que a mobilidade tem sobre a evolução das cidades, a construção de rodovias foi uma das formas encontradas para que este desenvolvimento fosse alcançado. Uma vez compreendida a questão da proteção do ambiente onde o empreendimento se incorpora, com o homem e sua qualidade de vida também inseridos neste princípio, busca-se garantir que os projetos de engenharia sejam eficientes, tanto para quem trafega pela rodovia, quanto para a população dos municípios influenciados (NEVES e HENKES, 2013 apud ROMAN, 2016).

Nesse sentido, o presente trabalho, além de atualizar o levantamento de aspectos e impactos ambientais para cumprir o item 6.1.2 da Norma, também visa identificar as mudanças oriundas da Norma ABNT NBR ISO 14001:2015 para os demais itens, com vistas a contribuir para a transição do Sistema, ou seja, é esperado que este estudo sirva de base inicial para a possível atualização do SGA da organização, bem como para implementação de SGA em empresas do ramo. A recente edição da Norma estabelece o período de três anos após a publicação (23 de setembro 
de 2015) para que todas as empresas certificadas atualizem os seus sistemas de gestão ambiental, de acordo com os novos requisitos da Norma.

\section{OBJETIVOS}

\subsection{Objetivo geral}

Propor adequação do Sistema de Gestão Ambiental da Concessionária da Rodovia Osório - Porto Alegre S.A. (Triunfo Concepa), em relação ao item 6 "Planejamento", especificamente ao subitem 6.1.2 "Aspectos Ambientais" da Norma ABNT NBR ISO 14001:2015.

\subsection{Objetivos especificos}

- Identificar os requisitos do Sistema de Gestão Ambiental da empresa Triunfo Concepa que deverão ser atualizados, conforme a nova edição da Norma ABNT NBR ISO 14001:2015;

- Revisar o documento interno da organização "Gerenciamento de Aspectos e Impactos Ambientais (IT-200-03)", com vistas à atualização e adaptação do documento "LAIA MATRIZ DE AVALIAÇÃO DE IMPACTOS AMBIENTAIS - RQ 200-04";

- Estruturar uma nova matriz para a atualização dos aspectos e impactos ambientais, relacionados as atividades de conservação da faixa de domínio, utilização da rodovia pelos usuários e armazenamento temporário de resíduos.

\section{2. ÁREA DE ESTUDO}

Em dezembro de 1996, o Consórcio formado entre a Construtora Triunfo S.A. e a empresa SBS Engenharia e Construções foi homologado vencedor da licitação da concessão da BR-290, sendo o contrato assinado em 04 de março de 1997 e a rodovia 
transferida para a administração da Concessionária da Rodovia Osório - Porto Alegre S.A. - CONCEPA (Triunfo Concepa), formada exclusivamente para este fim em 04 de julho de 1997. (CONCEPA, 2018a)

A concessão foi outorgada pelo Governo Federal, no âmbito do Programa Federal de Concessões Rodoviárias, e tem por objeto a exploração da Rodovia BR290, no trecho que liga os municípios de Osório, Porto Alegre e Guaíba (entroncamento da Rodovia BR-116), no estado do Rio Grande do Sul (CONCEPA, 2018a).

A Triunfo Concepa administrava 121 quilômetros de rodovias duplicadas, com três praças de pedágios, sendo duas unidirecionais (km 19 - Santo Antônio da Patrulha e km 110 - Eldorado do Sul) e uma bidirecional (km 77 - Gravataí), com 58 cabines de cobrança manuais e nove cabines de cobrança automática. Primeira concessão rodoviária federal do Estado, a Concepa deteve um contrato de 20 anos, prorrogado por mais 1 ano, supervisionado pela Agência Nacional de Transportes Terrestres, ANTT, até julho de 2018 (CONCEPA, 2018a). O mapa da Figura 5 expõe a rodovia administrada pela concessionária.

Figura 5 - Abrangência da Licença de Operação № 2056/2014-DL.

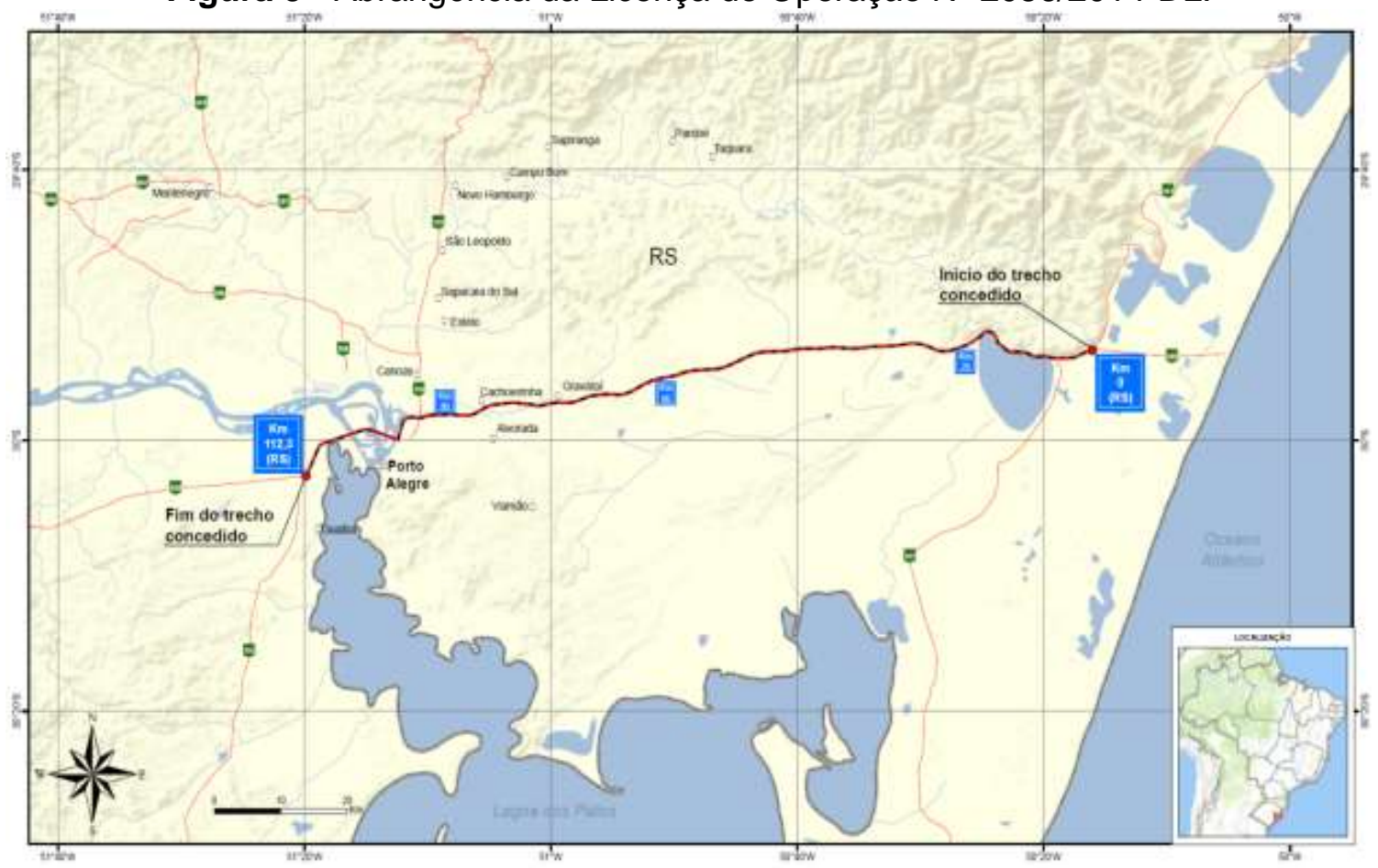

Fonte: FEPAM, 2014. 
O presente estudo foi executado no setor de SGI (Sistema de Gestão Integrada) da empresa, no período de 18 de dezembro de 2017 a 17 de junho de 2018. A empresa estava certificada pelas Normas ABNT NBR ISO 14001:2004 e ABNT NBR ISO 9001:2009 pela certificadora British Standards Institution (BSI), desde 2012, conforme certificados apresentados na Figura 6.

Figura 6 - Certificados do Sistema de Gestão.

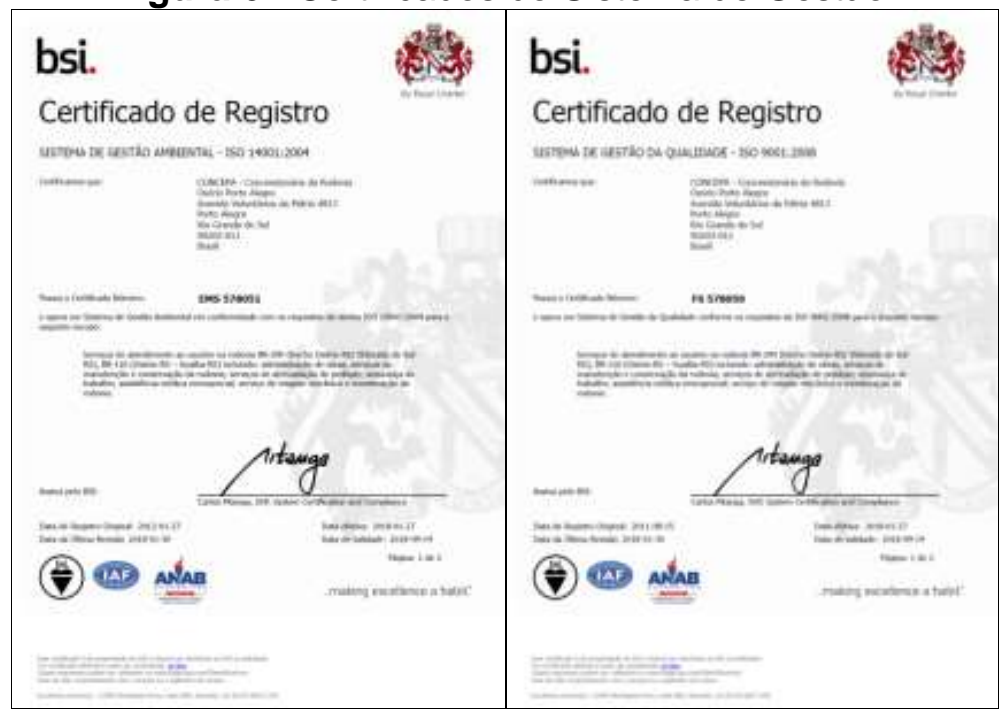

Fonte: CONCEPA, 2018b.

A gestão ambiental era praticada por meio da educação de seus colaboradores para manter e aplicar a política estabelecida pela alta direção (Figura 7), bem como os monitoramentos, controles internos e a gestão dos resíduos sólidos. 
Figura 7 - Política do Sistema de Gestão.

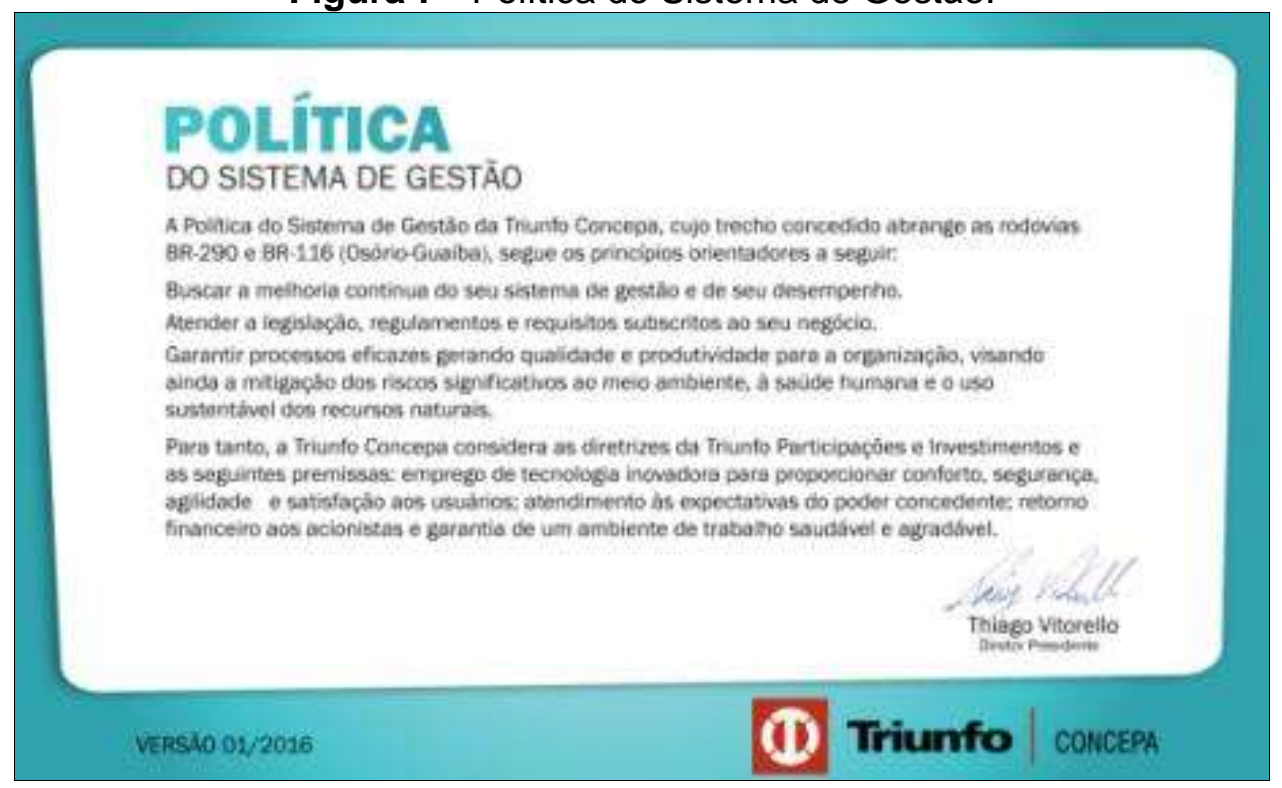

Fonte: CONCEPA, 2018c.

O setor de SGI desenvolve os procedimentos de controle de documentos, tratamento de não conformidades, ações preventivas e corretivas, auditorias internas, identificação e gestão dos aspectos e impactos ambientais, bem como controle de legislação aplicável.

A organização operava o Sistema de Gestão Ambiental em conformidade com os requisitos da Norma ISO 14001:2004 para o seguinte escopo: serviços de atendimento ao usuário na rodovia BR-290 (trecho Osório-RS/ Eldorado do Sul-RS), BR-116 (OsórioRS - Guaíba-RS), incluindo: administração de obras, serviços de manutenção e conservação da rodovia; serviços de arrecadação de pedágio; segurança do trabalho; assistência médica emergencial; serviço de resgate mecânico e monitoração da rodovia.

\section{METODOLOGIA}

O presente trabalho utilizou metodologia exploratória, sendo conduzido pelas ações metodológicas descritas a seguir. Em um primeiro momento, foi realizada a revisão do Sistema de Gestão Ambiental atual da empresa, que está baseado na versão 2004 da Norma ABNT NBR ISO 14001. Através do estudo minucioso e 
comparativo da Norma ABNT NBR ISO 14001 versão de 2004 e versão 2015, foram identificados os requisitos estabelecidos pela nova edição da Norma, o que resultou em um diagnóstico, contendo a descrição dos requisitos e as principais mudanças.

A partir do diagnóstico, foi identificado o item "6.1.2 Aspectos Ambientais", da versão 2015, como o requisito de maior relevância no presente momento, pois trata-se de uma premissa na etapa de implementação do SGA.

Com base na metodologia atual de avaliação dos aspectos ambientais utilizada pela empresa, estabelecida em procedimento interno (IT-200-03), procedeu-se ao levantamento detalhado e aplicado dos aspectos sujeitos à atualização ou que por ventura não haviam sido contemplados no estudo realizado anteriormente, para cumprimento da versão 2004 da Norma.

Para essa etapa, levou-se em conta as alterações do requisito 6.1.2 "Aspectos Ambientais", trazidas pela Norma ABNT NBR ISO 14001:2015; demais orientações da Norma ISO 14004:2016 e a análise de documentos referentes aos requisitos legais da organização. Além disso, para o completo atendimento do item 6.1.2 foram coletadas informações através do acompanhamento das práticas realizadas na rodovia, bem como na Central de Resíduos da empresa.

A ABNT NBR ISO 14001 não especifica a metodologia para determinar aspectos e impactos ambientais, mas convém que o método e os critérios utilizados forneçam resultados coerentes. Nesse sentido, o presente estudo manteve a metodologia existente, descrita a seguir.

Primeiramente, é feita a seleção da atividade, produto ou serviço, sendo extenso (a) o suficiente para a análise das entradas e saídas, associadas às atividades passadas, presentes e/ou futuras, considerando as condições normais e anormais de operação, bem como situações potenciais e reais de emergência. Posteriormente, é realizada a identificação do impacto relacionado ao aspecto ambiental, ou seja, identifica-se a alteração que esse aspecto causaria ao ambiente.

Finalizada a etapa de identificação dos aspectos e impactos ambientais, estes são caracterizados com o propósito de permitir uma melhor avaliação e definição dos métodos de gerenciamento e priorização daqueles considerados significativos. Desse modo, todas essas informações serviram de subsídio para a construção e atualização 
da "Matriz de Avaliação de Aspectos e Impactos Ambientais", documento interno (RQ 200-004), da empresa Triunfo Concepa.

\section{RESULTADOS E DISCUSSÕES}

Os resultados serão apresentados em dois momentos. Inicialmente, será brevemente abordada uma avaliação dos requisitos mais relevantes para este trabalho, comparando as duas versões da Norma. A segunda etapa, apresentará a atualização da "Matriz de Avaliação de Aspectos e Impactos Ambientais", documento interno (RQ 200-004) da empresa Triunfo Concepa.

\subsection{Novos requisitos da Norma}

Como um dos norteadores do trabalho, foi usada a Tabela 1, que expõe as correspondências entre as duas versões da Norma, disponível no anexo da ABNT NBR ISO 14001:2015.

As Normas de Sistema de Gestão até hoje apresentavam, cada uma, diferentes linguagens, estruturas e requisitos. Para abordar este problema, a ISO desenvolveu 0 Anexo SL - a nova estrutura de alto nível (HLS) que apresenta uma estrutura comum para todos os sistemas de gestão (BSI, 2015). Com isso, a Norma passa a incluir, além dos 3 requisitos introdutórios usuais, 7 requisitos básicos comuns a todas as Normas de sistema de gestão, são eles: Contexto da Organização, Liderança, Planejamento, Apoio, Operação, Avaliação de Desempenho e Melhoria.

O principal objetivo da revisão da Norma é fornecer um conjunto de requisitos comuns e estáveis para, pelo menos, os próximos 10 (dez) anos. Isso será possível devido à exigência dessa estrutura como base, que fornece uma apresentação mais coerente dos requisitos, em vez de um modelo para documentar as políticas, objetivos e processos (BVQI, 2015). 
Tabela 1 - Correspondência entre a ABNT NBR ISO 14001:2015 e a ABNT NBR ISO 14001:2004.

\begin{tabular}{|c|c|c|c|}
\hline \multicolumn{2}{|l|}{ ABNT NBR ISO 14001:2015 } & \multicolumn{2}{|c|}{ ABNT NBR ISO 14001:2004 } \\
\hline Título da Seção & $\begin{array}{c}\text { Número } \\
\text { da } \\
\text { Seção }\end{array}$ & $\begin{array}{c}\text { Número } \\
\text { da } \\
\text { Seção }\end{array}$ & Título da Seção \\
\hline Introdução & & & Introdução \\
\hline Escopo & 1 & 1 & Escopo \\
\hline Referências normativas & 2 & 2 & Referências normativas \\
\hline Termos e definições & 3 & 3 & Termos e definições \\
\hline $\begin{array}{l}\text { Contexto da organização (somente } \\
\text { título) }\end{array}$ & 4 & & \\
\hline & & 4 & $\begin{array}{l}\text { Requisitos do sistema da gestão } \\
\text { ambiental (somente título) }\end{array}$ \\
\hline $\begin{array}{l}\text { Entendendo a organização e seu } \\
\text { contexto }\end{array}$ & 4.1 & & \\
\hline $\begin{array}{l}\text { Entendendo as necessidades e } \\
\text { expectativas de partes interessadas }\end{array}$ & 4.2 & & \\
\hline $\begin{array}{l}\text { Determinando o escopo do sistema de } \\
\text { gestão ambiental }\end{array}$ & 4.3 & 4.1 & Requisitos gerais \\
\hline Sistema de gestão ambiental & 4.4 & 4.1 & Requisitos gerais \\
\hline Liderança (somente título) & 5 & & \\
\hline Liderança e comprometimento & 5.1 & & \\
\hline Política ambiental & 5.2 & 4.2 & Política ambiental \\
\hline $\begin{array}{l}\text { Papéis, responsabilidades e } \\
\text { autoridades organizacionais }\end{array}$ & 5.3 & 4.4.1 & $\begin{array}{l}\text { Recursos, funções, } \\
\text { responsabilidades e autoridades }\end{array}$ \\
\hline Planejamento (somente título) & 6 & 4.3 & Planejamento (somente título) \\
\hline $\begin{array}{l}\text { Ações para abordar riscos e } \\
\text { oportunidades (somente título) }\end{array}$ & 6.1 & & \\
\hline Generalidades & 6.1 .1 & & \\
\hline Aspectos ambientais & 6.1 .2 & 4.3.1 & Aspectos ambientais \\
\hline Requisitos legais e outros requisitos & 6.1 .3 & 4.3 .2 & Requisitos legais e outros \\
\hline Planejamento de ações & 6.1 .4 & & \\
\hline
\end{tabular}




\begin{tabular}{|c|c|c|c|}
\hline \multicolumn{2}{|c|}{ ABNT NBR ISO 14001:2015 } & \multicolumn{2}{|r|}{ ABNT NBR ISO 14001:2004 } \\
\hline Título da Seção & $\begin{array}{l}\text { Número da } \\
\text { Seção }\end{array}$ & $\begin{array}{l}\text { Número } \\
\text { da Seção }\end{array}$ & Título da Seção \\
\hline $\begin{array}{l}\text { Objetivos ambientais e } \\
\text { planejamento para alcançá-los } \\
\text { (somente título) }\end{array}$ & 6.2 & \multirow{3}{*}{ 4.3.3 } & \multirow{3}{*}{ Objetivos, metas e programa(s) } \\
\hline Objetivos ambientais & 6.2 .1 & & \\
\hline $\begin{array}{l}\text { Planejamento de ações para } \\
\text { alcançar os objetivos ambientais }\end{array}$ & 6.2 .2 & & \\
\hline Apoio (somente título) & 7 & 4.4 & $\begin{array}{l}\text { Implementação e operação (somente } \\
\text { título) }\end{array}$ \\
\hline Recursos & 7.1 & 4.4.1 & $\begin{array}{l}\text { Recursos, funções, responsabilidades } \\
\text { autoridades }\end{array}$ \\
\hline Competência & 7.2 & \multirow{2}{*}{4.4 .2} & \multirow{2}{*}{$\begin{array}{l}\text { Competência, treinamento e } \\
\text { conscientização }\end{array}$} \\
\hline Conscientização & 7.3 & & \\
\hline Comunicação (somente título) & 7.4 & \multirow{4}{*}{4.4 .3} & \multirow{4}{*}{ Comunicação } \\
\hline Generalidades & 7.4.1 & & \\
\hline Comunicação interna & 7.4 .2 & & \\
\hline Comunicação externa & 7.4 .3 & & \\
\hline $\begin{array}{l}\text { Informação documentada } \\
\text { (somente título) }\end{array}$ & 7.5 & \multirow[t]{2}{*}{4.4 .4} & \multirow[t]{2}{*}{ Documentação } \\
\hline Generalidades & 7.5 .1 & & \\
\hline \multirow{2}{*}{ Criando e atualizando } & \multirow{2}{*}{7.5 .2} & 4.4 .5 & Controle de documentos \\
\hline & & 4.5 .4 & Controle de registros \\
\hline \multirow{2}{*}{$\begin{array}{l}\text { Controle de informação } \\
\text { documentada }\end{array}$} & \multirow{2}{*}{ 7.5.3 } & 4.4 .5 & Controle de documentos \\
\hline & & 4.5 .4 & Controle de registros \\
\hline Operação (somente título) & 8 & 4.4 & $\begin{array}{l}\text { Implementação e operação (somente } \\
\text { título) }\end{array}$ \\
\hline
\end{tabular}




\begin{tabular}{|c|c|c|c|}
\hline \multicolumn{2}{|l|}{ ABNT NBR ISO 14001:2015 } & \multicolumn{2}{|r|}{ ABNT NBR ISO 14001:2004 } \\
\hline Título da Seção & $\begin{array}{l}\text { Número } \\
\text { da } \\
\text { Seção }\end{array}$ & $\begin{array}{l}\text { Número } \\
\text { da } \\
\text { Seção }\end{array}$ & Título da Seção \\
\hline $\begin{array}{l}\text { Planejamento e controle } \\
\text { operacionais }\end{array}$ & 8.1 & 4.4.6 & Controle operacional \\
\hline $\begin{array}{l}\text { Preparação e resposta a } \\
\text { emergências }\end{array}$ & 8.2 & 4.4 .7 & Preparação e resposta a emergências \\
\hline $\begin{array}{l}\text { Avaliação de desempenho } \\
\text { (somente título) }\end{array}$ & 9 & 4.5 & Verificação (somente título) \\
\hline $\begin{array}{l}\text { Monitoramento, medição, análise e } \\
\text { avaliação (somente título) }\end{array}$ & 9.1 & \multirow[t]{2}{*}{4.5 .1} & \multirow[t]{2}{*}{ Monitoramento e medição } \\
\hline Generalidades & 9.1 .1 & & \\
\hline $\begin{array}{l}\text { Avaliação do atendimento aos } \\
\text { requisitos legais e outros requisitos }\end{array}$ & 9.1 .2 & 4.5 .2 & $\begin{array}{l}\text { Avaliação do atendimento a requisitos } \\
\text { legais e outros }\end{array}$ \\
\hline Auditoria interna (somente título) & 9.2 & \multirow{3}{*}{4.5 .5} & \multirow{3}{*}{ Auditoria interna } \\
\hline Generalidades & 9.2 .1 & & \\
\hline Programa de auditoria interna & 9.2 .2 & & \\
\hline Análise crítica pela direção & 9.3 & 4.6 & Análise pela administração \\
\hline Melhoria (somente título) & 10 & & \\
\hline Generalidades & 10.1 & & \\
\hline Não conformidade e ação corretiva & 10.2 & 4.5 .3 & $\begin{array}{l}\text { Não conformidade, ação corretiva e } \\
\text { ação preventiva }\end{array}$ \\
\hline Melhoria contínua & 10.3 & & \\
\hline Orientação para uso desta Norma & Anexo A & Anexo A & Orientações para uso desta Norma \\
\hline \multirow[t]{2}{*}{$\begin{array}{l}\text { Correspondência entre a ABNT } \\
\text { NBR ISO 14001:2015 e a ABNT } \\
\text { NBR ISO 14001:2004 }\end{array}$} & Anexo B & & \\
\hline & & Anexo B & $\begin{array}{l}\text { Correspondências entre a } \\
\text { ABNT NBR ISO 14001:2004 e a ABNT } \\
\text { NBR ISO 9001:2000 }\end{array}$ \\
\hline Bibliografia & & & Bibliografia \\
\hline Índice alfabético de termos & Índice & & \\
\hline
\end{tabular}

Fonte: ABNT, 2015. 
A seguir, serão descritos os requisitos da Norma ABNT NBR ISO 14001:2015 mais relevantes para este tabalho.

Considerada como um todo, o requisito 6 apresenta provavelmente a maior mudança para os usuários de versões anteriores da Norma (BSI, 2015). Dessa maneira, a fase de planejamento, especificamente o requisito 6.1.2, será melhor apresentada e discutida na segunda etapa dos resultados deste trabalho (item 5. Levantamento e Aspectos e Impactos Ambientais), com as mudanças estabelecidas neste requisito, sendo aplicadas na área de estudo em questão.

A versão de 2004 já mencionava a necessidade de identificar todos os aspectos que a organização controla e influencia. Embora nas orientações para uso da Norma o conceito estivesse subentendido, nesta versão é deixado claro que a determinação e avaliação dos aspectos deve considerar o ciclo de vida, o que é posteriormente reforçado na fase de operação (APCER, 2016). Os estágios do ciclo de vida incluem a aquisição da matéria-prima, projeto, produção, transporte/entrega, uso, tratamento pósuso e disposição final (ABNT, 2015).

A organização determina os riscos e as oportunidades, incluindo os resultantes dos aspectos ambientais significativos e dos requisitos legais (6.1). Deve decidir e planejar as ações necessárias para atingir os resultados pretendidos e assegurar a melhoria do desempenho ambiental. O conceito de pensamento baseado no risco estava subentendido nas edições anteriores através dos requisitos de planejamento, revisão e melhoria. Nesta versão, os requisitos para a determinação de riscos e oportunidades são base para o planejamento do SGA (ABNT, 2015).

A determinação de situações de emergência potenciais, que antes estavam associadas à implementação e operação, agora foram incluídas na fase de planejamento (APCER, 2016). A obrigatoriedade de estabelecer metas para os objetivos foi eliminada (6.2), entretanto, foi apontada a necessidade de monitorar, comunicar e atualizar os objetivos. Os critérios para a sua definição incluem agora os riscos e oportunidades determinados (APCER, 2016).

Os critérios para determinação da significância dos aspectos devem ser documentados e os aspectos significativos a níveis e funções relevantes devem ser comunicados internamente, conforme apropriado. O planejamento de ações agora é 
abordado para tratar os aspectos ambientais significativos, requisitos legais e riscos e oportunidades. A eficácia destas ações deve ser avaliada (APCER, 2016).

Através das mudanças da versão 2015 da Norma ABNT NBR ISO 14001, podese garantir que a gestão ambiental está alinhada com a alta direção da organização, pois introduz uma abordagem integrada com outras Normas de sistemas de gestão, devido à estrutura de alto nível, o que aumenta o envolvimento da equipe de liderança e melhora o desempenho ambiental da empresa.

\subsection{Levantamento de Aspectos e Impactos Ambientais}

No ciclo PDCA, a etapa de planejamento é o primeiro passo para alcançar a melhoria contínua. Essa fase representa o processo inicial exigido na implantação de qualquer SGA em uma organização que busca a certificação da ISO 14001. Dessa forma, o presente trabalho tem o objetivo de revisar e atualizar a principal ferramenta do requisito 6.1.2 da Norma, o Levantamento de Aspectos e Impactos Ambientais - LAIA, que é de fundamental importância para a implantação e implementação do SGA.

Aspecto ambiental é o elemento das atividades, produtos ou serviços de uma organização que interage ou pode interagir com o meio ambiente (ABNT, 2015).

No que tange ao conceito "impacto", da perspectiva legal, a Resolução CONAMA no 001/1986, em seu artigo 1, define impacto ambiental como:

(...) qualquer alteração das propriedades físicas, químicas ou biológicas do meio ambiente, causada por qualquer forma de matéria ou energia resultante das atividades humanas, que direta ou indiretamente afetem: I) a saúde, a segurança e o bem estar da população; II) as atividades sociais e econômicas; III) as condições estéticas e sanitárias do meio ambiente; IV) a qualidade dos recursos ambientais. (BRASIL, 1986)

Segundo as orientações de uso da Norma, as alterações para o meio ambiente, adversas ou benéficas, que resultem total ou parcialmente dos aspectos ambientais, são chamadas de impactos ambientais. A relação entre os aspectos e impactos ambientais é de causa e efeito (ABNT, 2015).

A determinação dos aspectos ambientais significativos é um processo contínuo, o que melhora o entendimento da organização da sua relação com o meio ambiente e 
contribui para a melhoria contínua do desempenho ambiental da organização, através de aprimoramento de seu Sistema de Gestão Ambiental (ISO, 2016b).

Através de procedimento interno (IT-200-03), são identificados os aspectos e avaliados os impactos ambientais associados a estes, sendo descrita a sistemática para gerenciamento dos mesmos. A metodologia para a caracterização dos aspectos ambientais da Triunfo Concepa é baseada, atualmente, nos critérios listados abaixo:

\section{Tipo de controle exercido}

Incidência Direta (D) - Impactos decorrentes das atividades da empresa sobre as quais exerce controle.

Incidência Indireta (I) - Impactos decorrentes de atividades de terceiros, sobre as quais a empresa exerce apenas influência.

\section{Situação operacional}

Relaciona a situação em que ocorre o impacto ou a atividade a ele associado.

Normal (N) - Relativos à rotina diária, inclusive manutenção.

Anormal (A) - Associados a operações não rotineiras (reformas de instalações, obras de manutenção, alterações em rotinas por motivos específicos).

Emergência (E) - Associados a situações não planejadas, de emergência inerentes à atividade/operação e com potencial de causar impacto ambiental.

\section{Temporalidade}

Determina em que tempo o aspecto ambiental foi gerado:

Passado $(P)$ - Impacto identificado no presente, porém decorrente de atividade desenvolvida no passado e que tenha gerado algum passivo.

Atual/Presente (A) - Impactos de atividades e processos no presente (decorrente de atividade atual). 
Futuro (F) - Impactos/danos previsíveis de alterações de processo, operações, atividades, produtos e serviços a serem implementados.

Para avaliação do impacto, é atribuída uma pontuação para cada um dos seguintes critérios:

\section{Severidade}

Apresenta a gravidade do impacto ambiental associado ao aspecto relacionado.

Alta (5) - Causa modificações severas ao meio ambiente ou cujos efeitos são considerados irreversíveis devido ao longo prazo ou elevado custo para remediação.

Média (3) - Causa modificações relevantes cujos efeitos alteram de forma significativa o meio ambiente, mas podem ser revertidos em médio prazo.

Baixa (1) - Causa pequenos danos ou danos desprezíveis ao meio ambiente, reversíveis em um pequeno intervalo de tempo e que podem ser mitigados por ação imediata e/ou pela simples regeneração do próprio meio.

\section{Frequência}

Contínua (5) - O aspecto ambiental ocorre frequentemente. Eventos regulares e repetitivos, consumos ininterruptos.

Periódica (3) - O aspecto ambiental ocorre periódica ou regularmente, eventos planejados que ocorrem em intervalos de tempo com alguma regularidade.

Esporádica (1) - O aspecto ambiental ocorre rara ou esporadicamente, eventos não planejados e eventuais que ocorrem sem regularidade.

\section{Abrangência}

Global (5) - Aquele cujos efeitos do impacto ambiental atingem um componente ambiental de importância coletiva, nacional ou até mesmo internacional.

Regional (3) - Aquele cujos efeitos do impacto ambiental se propagam por uma área além das imediações do sítio onde se dá a ação. 
Local (1) - Aquele cujos efeitos do impacto ambiental se fazem sentir apenas na própria organização onde se deu a ação e suas imediações.

\section{Probabilidade}

Apresenta a probabilidade de ocorrência do aspecto associado ao impacto ambiental analisado. Ao analisar as atividades, é observado com que frequência ocorrem os aspectos ambientais. Para aspectos emergenciais, deve-se considerar a probabilidade de ocorrência e não a frequência.

Provável (5) - Existe relato de acontecimentos do evento no período de 01 ano.

Remota (3) - Existe relato de acontecimentos do evento no período entre 01 ano e 03 anos.

Improvável (1) - Existe relato de acontecimentos do evento somente em períodos acima de 03 anos ou mais.

A classificação dos aspectos ambientais quanto à sua significância é obtida através da multiplicação entre os conceitos determinados para os critérios de severidade, probabilidade e frequência de cada impacto ambiental. De acordo com o resultado, o aspecto ambiental é classificado, conforme segue:

Acima de 45 - Aspecto ambiental significativo (S)

Até 45 - Aspecto ambiental não significativo (N)

Com base nos critérios descritos acima, a "Matriz de Levantamento de Aspectos e Impactos Ambientais (RQ 200-04) é atualmente estruturada, conforme exposto na Figura 8.

Figura 8 - Cabeçalho da Matriz de Levantamento de Aspectos e Impactos Ambientais - LAIA.

\begin{tabular}{|c|c|c|c|c|c|c|c|c|c|c|c|c|}
\hline \multirow{2}{*}{ Area } & \multirow{2}{*}{ Processo } & \multirow{2}{*}{ Atividade } & \multicolumn{4}{|c|}{ Aspecto ambiental / Caracterizaçào } & \multirow{2}{*}{$\begin{array}{c}\begin{array}{c}\text { Impscto } \\
\text { ambiental } \\
\text { astociado }\end{array} \\
\text { Descriţajo }\end{array}$} & \multicolumn{3}{|c|}{ Avaliaçào do impacto } & Classificaçắo & \multirow{2}{*}{$\begin{array}{c}\text { Controle(s) } \\
\text { operacional(is) } \\
\text { existente(s) }\end{array}$} \\
\hline & & & Descriçào & $\begin{array}{l}\text { Tipo de } \\
\text { controle }\end{array}$ & Situaçäo & Temporalidade & & Severidade & $\begin{array}{c}\text { Frequèncial } \\
\text { Probabilidade }\end{array}$ & Abrangencia & Significativo & \\
\hline
\end{tabular}

Fonte: CONCEPA, 2018d. 
Para os aspectos ambientais significativos, foram informados os controles operacionais existentes. Segundo Gallardo (2004), o sucesso na implementação de medidas de prevenção e mitigação remete à adoção de um detalhado programa de monitoramento ambiental e ao rigoroso controle de sua realização.

Atualmente, para cumprir o requisito 4.3.1 da ISO 14001:2004, as atividades da organização são avaliadas através da matriz de levantamento de aspectos e impactos ambientais, apresentada na Tabela 2. Foram selecionadas 3 (três) atividades para a realização deste trabalho, quais sejam: utilização da rodovia pelos usuários; conservação da faixa de domínio e armazenamento temporário de resíduos.

A seleção destas 3 (três) atividades considerou a relevância das mesmas dentro do escopo do SGA, sendo diretamente relacionadas ao ramo de atuação da empresa. Também foi levado em consideração a relação delas com o meio ambiente, devido a significância dos impactos envolvidos na operação da rodovia.

Destaque neste Levantamento de Aspectos Ambientais, a "Utilização da rodovia pelos usuários (Atividade 1)" consta no documento "Plano de Exploração da Rodovia PER”, o qual prioriza as condições do usuário (ANTT, 2015). Além disso, estabelece que o objetivo principal da concessão é ter uma rodovia confortável, segura, condizente e adequada às circunstâncias da época, respeitando as condições sócio-econômicas médias do usuário, ou seja, é a principal atividade da empresa.

A “Conservação da faixa de domínio (Atividade 2)" se carateriza pela manutenção do canteiro central e faixas de domínio. Essas ações têm como objetivo manter essas áreas adequadamente tratadas, sob os aspectos de segurança, controle de acessos e paisagismos, visando assegurar a proteção física e operacional da rodovia, prolongando a sua vida útil e de seus elementos.

O "Armazenamento temporário de resíduos (Atividade 3)" consiste na coleta e armazenamento dos resíduos sólidos coletados na rodovia. $O$ armazenamento temporário ocorre na Área de Depósito Temporário de Resíduos (ADTR), que é organizada e mantida, conforme descrito no Plano de Gerenciamento de Resíduos Sólidos (PGRS) da empresa. Esta central é exclusiva para resíduos Classe II - não perigosos, conforme a ABNT NBR 10004, que classifica os resíduos sólidos quanto aos seus riscos potenciais ao meio ambiente e à saúde pública (ABNT, 2004b). 
Tabela 2 - Atual Matriz de Avaliação de Impactos Ambientais.

\begin{tabular}{|c|c|c|c|c|c|c|c|c|c|c|c|c|}
\hline \multirow{2}{*}{ Area } & \multirow{2}{*}{ Processo } & \multirow{2}{*}{ Atividade } & \multicolumn{4}{|c|}{ Aspocto ambiental | Caractorizaçäo } & \multirow{2}{*}{$\begin{array}{l}\text { Impacto anbiental associado } \\
\text { Descriçào }\end{array}$} & \multicolumn{3}{|c|}{ Avaliaç̧̇o do impacto } & Classticap̧äo & \multirow{2}{*}{ Controle(s) cperacional(is) existente(s) } \\
\hline & & & Descriçào & $\begin{array}{l}\text { Tipo de } \\
\text { controle }\end{array}$ & Situaçào & $\underset{\text { ade }}{\text { Temporalid }}$ & & Severidade & $\begin{array}{c}\text { Frequêncial } \\
\text { Probabilidado }\end{array}$ & Abrangencia & Significativo & \\
\hline \multirow{10}{*}{$\begin{array}{l}\text { कृ } \\
\frac{0}{0} \\
\frac{0}{0} \\
\text { ơ }\end{array}$} & \multirow{10}{*}{$\begin{array}{l}\frac{8}{8} \\
\text { क्ष } \\
8\end{array}$} & \multirow{10}{*}{ 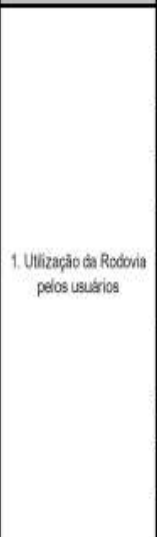 } & $\begin{array}{l}\text { Vazamento de prodions paligoscos liquidos ne } \\
\text { rodovia }\end{array}$ & 1 & E & A & 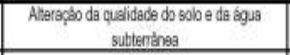 & 5 & 3 & 3 & N & Plano de Açāo de Emergència (PAE) \\
\hline & & & $\begin{array}{l}\text { Vazamentio de produtos perigcscas liquidos em } \\
\text { recurso hidtico. }\end{array}$ & 1 & E & A & Alteraçalo da qualidade do recurso hidrico & 5 & 3 & 5 & 8 & PAE \\
\hline & & & Vazamerto da diladigaxa & 1 & E & A & $\begin{array}{l}\text { Aliaragso da qualidade do solo e da gyua } \\
\text { sutterínea }\end{array}$ & 5 & 3 & 3. & N & PAE \\
\hline & & & $\begin{array}{l}\text { Dispersto de proditos parigcoces solidos na } \\
\text { rodovia }\end{array}$ & 1 & E & A & $\begin{array}{c}\text { Altaraça da qualidade do solo a da água } \\
\text { subterinas }\end{array}$ & 5 & 3 & 3 & N & PAE \\
\hline & & & $\begin{array}{l}\text { Dispersào de produtos parigcses sobldoses am } \\
\text { recurso hidrico }\end{array}$ & 1 & E & A & Attreaça da qualidate do recurso hidrico & 5 & 3 & 3 & N & PAE \\
\hline & & & Risco do incentiviexplasio & 1 & E & A & 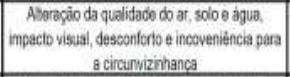 & 5 & 5 & 3 & 8. & PAE \\
\hline & & & hoándio na vegeiscáo & 1 & E & A & 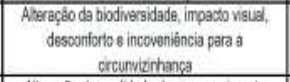 & 5 & 5 & 3 & 8 & PAE \\
\hline & & & 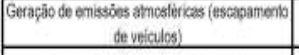 & 1 & N & A & 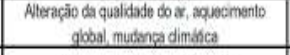 & 3 & 5 & 3 & N & \\
\hline & & & Gersach de residues pelos usuartos & 1 & N & A & Alteraçăo da qualidade do sodo & 3 & 5 & 5 & s & 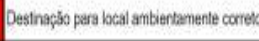 \\
\hline & & & Gorgajo de residuas de prous & 1 & A & A & Alteraçäio tin qualidade do solo & 3 & 5 & 3 & N & 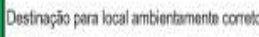 \\
\hline \multirow{9}{*}{ 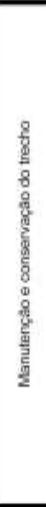 } & \multirow{9}{*}{ 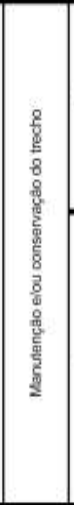 } & \multirow{4}{*}{$\begin{array}{c}\text { 2. Congenvarjo da faixa } \\
\text { de dominio }\end{array}$} & Supresstódo de vegetaria & 1 & $\mathrm{~N}$ & $\mathrm{~A}$ & Alteraç̧̧o da biodinersidade & 5 & 3 & 5 & 3 & Segir as condioonantes de licença \\
\hline & & & Gerapia de residuos pelos usuarios & 1 & N & A & Alteraçăo da qualidade do scio & 3 & 5 & 5 & 8 & 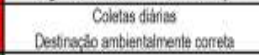 \\
\hline & & & Cereçáo de residus pels comiridade & 1 & N & A & Atteraçăo da qualidade do solo & 3 & 5 & 3 & n & 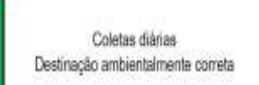 \\
\hline & & & Usoe onapacio dos solo & 1 & N & $\mathrm{A}$ & Allmacáa da gualidade bo solo & 5 & 3 & 5 & 1 & Segur as condiconantes de licanca \\
\hline & & \multirow{5}{*}{$\begin{array}{l}\text { 3. Ammazenemento } \\
\text { temporsio de residuces }\end{array}$} & Armazenamento da residuses elatioaletcinicos & 1 & N & A & Altereç̧ấ da qualidada do solo & 5 & 5 & 3 & $\$$ & Destnaç̧o pera bcal ambientamente coneto \\
\hline & & & 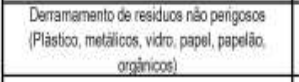 & 1 & N & A & Alterayāa da quaidado do sols a ága & 3 & 5 & 3 & N & 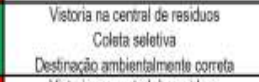 \\
\hline & & & Geraças de medeira & 1 & N & A & Aberaçato da qualidade do solo & 5 & 5 & 3 & $\$$ & 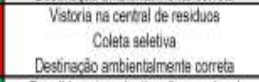 \\
\hline & & & Gercę̧o da residuos da variçäo & 1 & N & A & Alteraçào de qualidade do solo & 3 & 1 & 3 & N & $\begin{array}{l}\text { Recolhimertoo e desfinaçáa para local } \\
\text { ambientamento adequando }\end{array}$ \\
\hline & & & Disperş̉o de residuos ntáo perigcoos no solo & 1 & A & A & 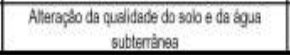 & 3 & 1 & 3 & $\mathrm{~N}$ & $\begin{array}{l}\text { Recolhimento e destinaçáp para local } \\
\text { ambiertaments adecuands }\end{array}$ \\
\hline
\end{tabular}

Fonte: CONCEPA, 2018d.

Para essas 3 (três) atividades, existem 19 (dezenove) aspectos considerados, sendo 9 (nove) desses classificados como significativos.

Com a atualização da Norma, houve a necessidade de inserção de novos critérios, os quais não estavam sendo considerados no documento "Matriz de Avaliação de Impactos Ambientais", conforme Figura 8, apresentada anteriormente. A Figura 9 apresenta a Matriz atualizada com a inserção dos seguintes aspectos ambientais, quais sejam: controle do ciclo de vida; significância cultural e classe. Ressalta-se que os critérios anteriormente considerados, foram mantidos na avaliação dos impactos ambientais. 
Figura 9 - Cabeçalho atualizado da matriz de Levantamento de Aspectos e Impactos Ambientais - LAIA.

\begin{tabular}{|c|c|c|c|c|c|c|c|c|c|c|c|c|c|c|c|}
\hline \multirow[b]{2}{*}{ Area } & \multirow{2}{*}{ Proceses } & \multirow[b]{2}{*}{ atovisade } & \multicolumn{7}{|c|}{ Aspesto antiemtul | Caractorsaçlo } & $\begin{array}{l}\text { Injpicto } \\
\text { ambiental }\end{array}$ & \multicolumn{3}{|c|}{ Avariaçes do ingacto } & \multirow{2}{*}{$\begin{array}{l}\text { Classificaçào } \\
\text { Significativo }\end{array}$} & \multirow{2}{*}{$\begin{array}{l}\text { Controle; }[\text { i) } \\
\text { operacibealis } \\
\text { oxistente(s) }\end{array}$} \\
\hline & & & $\begin{array}{l}\text { Controin } \\
\text { do Ciclo } \\
\text { de Xids }\end{array}$ & Descrigho & $\begin{array}{l}\text { Tipo de } \\
\text { controle }\end{array}$ & struaçio & Temporalidade & $\left|\begin{array}{c}\text { Signiteincia } \\
\text { Cultural }\end{array}\right|$ & Clessos & Desceiçäo & Severidade & $\begin{array}{l}\text { Frequèncial } \\
\text { Probabilidade }\end{array}$ & Abrangeocia & & \\
\hline
\end{tabular}

Fonte: Autor, 2018.

A primeira mudança realizada na matriz foi a inclusão do critério "Controle do Ciclo de Vida". Segundo a ISO 14004:2016, ao aplicar uma perspectiva de ciclo de vida de seus produtos e serviços, a organização deve considerar o grau de controle e influência que tem sobre os estágios do ciclo de vida.

Em suas orientações de uso (Anexo A), a ABNT NBR ISO 14001:2015 esclarece que uma avaliação detalhada do ciclo de vida não é necessária. Ao analisar o escopo do SGA em questão, entende-se que o estágio do ciclo de vida que a organização possui maior controle é com relação aos produtos que utiliza em suas atividades, sendo responsável pelo uso propriamente dito, a forma de utilização, o descarte e o método de eliminação destes produtos.

Ainda assim, é importante se ter uma visão geral do que está envolvido no ciclo de vida de uma rodovia, o que é possível através da obsevação da Figura 10. Ao considerarmos este contexto atrelado à Triunfo Concepa, por se tratar de um serviço, entende-se que as atividades estão inseridas na etapa de operação (manutenção e reparos) deste ciclo.

Figura 10 - Ciclo de vida das rodovias e limite do sistema.

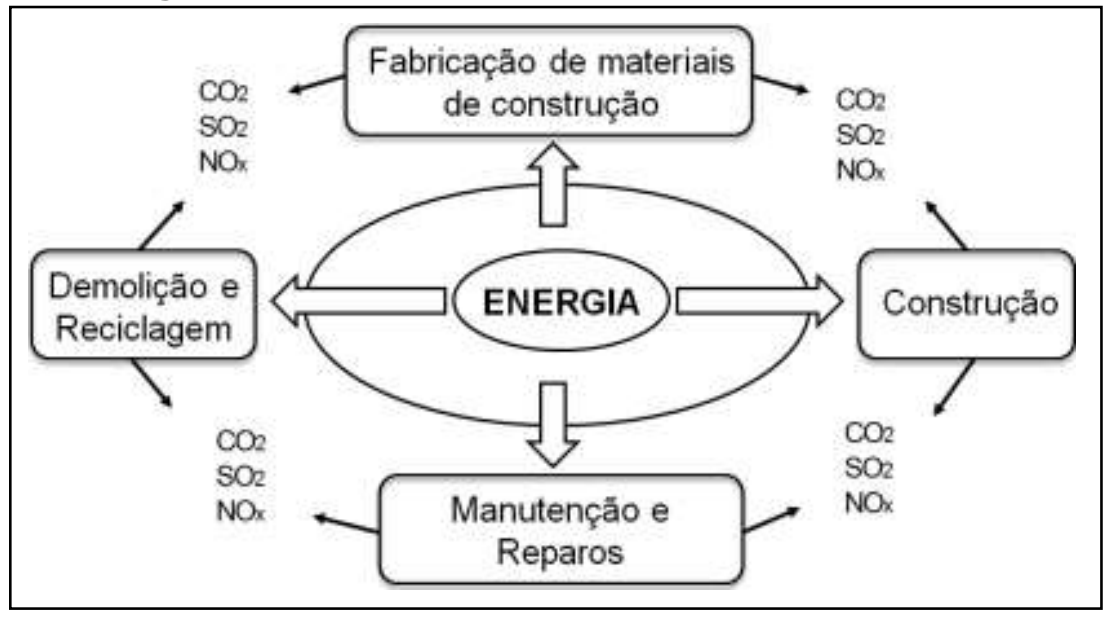

Fonte: Adaptado de PARK, et al. 2003. 
Considerando o exposto, foi usada a perspectiva do ciclo de vida no que tange as atividades da organização, para que seja mantido o foco no escopo deste SGA.

Dependendo do controle que a organização possui sob o ciclo de vida dos produtos atrelados às suas atividades, será classificado como:

Influenciável - A organização possui controle sob alguma das etapas do ciclo de vida dos produtos atrelados à esta atividade.

Não influenciável - A organização não possui controle sob o ciclo de vida de nenhum dos produtos atrelados à esta atividade.

O conceito de "Significância Cultural" foi considerado para estimar o valor de um local. Os locais que provavelmente serão considerados significativos são aqueles que ajudam a compreensão do passado, ou enriquecem o presente, e que serão úteis para as gerações futuras (TSUNOKAWA e HOBAN, 1997). Este conceito remete-se a visão geral do ciclo de vida de uma rodovia.

A avaliação de significância é a base para determinar qualquer ação que proteja os lugares culturais e que seja parte integrante de um plano de gerenciamento do local. Requer conhecimento profundo de arte e história arquitetônica, história social e conhecimento de materiais (TSUNOKAWA e HOBAN, 1997). Este novo critério classifica a significância cultural dos aspectos em:

Valor estético (E) - Envolvem um local que é moldado pelo histórico cultural, o design, o nível de manufatura e pela preferência dos usuários, sendo um atrativo para o público em geral.

Valor histórico $(\mathrm{H})$ - Envolvem um local marcado por uma cultura, grupo, período de tempo ou tipo de atividade humana, podendo até estar associado a um indivíduo em particular.

Valor científico (C) - Este valor dependerá da importância dos dados que podem ser obtidos no local envolvido, mais especificamente raridade, qualidade ou representatividade.

Valor social (S) - Este conceito abrange as qualidades pelas quais um lugar se torna foco para um determinado grupo pelo seu significado político, religioso, nacional ou cultural. 
Também foi inserido o critério "Classe" devido a nova abordagem da Norma ABNT NBR ISO 14001:2015, onde estabelece no requisito 6.1 que a organização deve determinar os riscos e oportunidades relacionados aos seus aspectos ambientais. Este critério tem o objetivo de detectar efeitos potenciais adversos (ameaças) e efeitos potenciais benéficos (oportunidades), com isso, os aspectos são classificados em:

Benéfico $(B)-O$ aspecto pode ter efeitos potenciais benéficos.

Adverso $(A)-O$ aspecto pode ter efeitos potenciais adversos.

Caso os aspectos gerem riscos e oportunidades para o SGA, deverão ser elaborados planos de ação para sua abordagem, a fim de assegurar que o Sistema possa alcançar os resultados pretendidos e a melhoria contínua.

Com a reconsideração dos impactos associados aos aspectos das atividades selecionadas e a inserção dos novos critérios, a matriz reformulada passa a se estruturar da seguinte forma, conforme a Tabela 3.

Tabela 3 - Matriz de avaliação de impactos ambientais reformulada.

\begin{tabular}{|c|c|c|c|c|c|c|c|c|c|c|c|c|c|c|c|}
\hline \multirow{2}{*}{ Ares } & \multirow{2}{*}{ Processo } & \multirow{2}{*}{ Asvidade } & \multicolumn{7}{|c|}{ Aspecto ambiental | Caractorizzajto } & Impacto ambiental associado & \multicolumn{3}{|c|}{ Avaliegto do impacto } & \multirow[b]{2}{*}{ Significestivo } & \multirow{2}{*}{ Controle(s) operacional(s) exiatente(s) } \\
\hline & & & \begin{tabular}{|l|} 
Conifrole \\
do Cielo \\
de Vida \\
\end{tabular} & Descriçato & $\begin{array}{l}\text { Tipo de } \\
\text { controle }\end{array}$ & Shuaça & $\begin{array}{c}\text { Temporalid } \\
\text { ade }\end{array}$ & $\begin{array}{l}\text { Significincia } \\
\text { Cultural }\end{array}$ & Clesse & Deseriçào & Severidace & $\begin{array}{l}\text { Frequèncla/ } \\
\text { Probablidade }\end{array}$ & Abrangencia & & \\
\hline \multirow{13}{*}{$\begin{array}{l}\frac{7}{5} \\
\frac{5}{80} \\
\frac{8}{8}\end{array}$} & \multirow{14}{*}{$\frac{9}{\frac{9}{8}}$} & \multirow{13}{*}{ 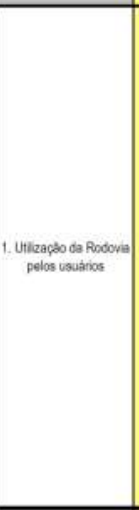 } & \multirow{14}{*}{ 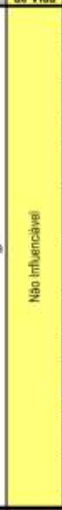 } & 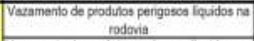 & 1 & E & A & c & A & 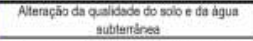 & 5 & 3 & 3 & N & PAE \\
\hline & & & & 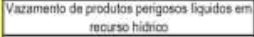 & 1 & E & A & $c$ & A & Alterageso de qualisdede do recurso hidico & 5 & 3 & 5 & 3 & PAE \\
\hline & & & & \begin{tabular}{|c|} 
Vazamento de cleodgraxa \\
\end{tabular} & 1 & E & A & c & A & 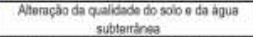 & 5 & 3 & 3 & N & PAE \\
\hline & & & & 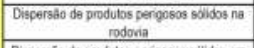 & 1 & $\varepsilon$ & A & c & A & 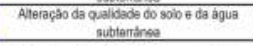 & 5 & 3 & 3 & N & PAE \\
\hline & & & & $\begin{array}{l}\text { Dispersaño de produtos perigosos szilidas em } \\
\text { reourso hidricos }\end{array}$ & 1 & $\varepsilon$ & A & c & A & Alteractoo da qual dade do recurso hidico & 3 & 3 & 3 & N. & PAE \\
\hline & & & & Riscos de incindoinglostio & 1 & $\varepsilon$ & A & c & A & 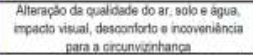 & 5 & 5 & 3 & s & PAE \\
\hline & & & & Inoterdo na vegotaçăo & 1 & E & A & c & A & 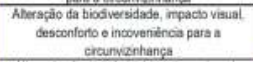 & 5 & 5 & 3 & $=$ & PAE \\
\hline & & & & 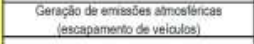 & 1 & N & A & c & A & 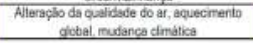 & 3 & 5 & 5 & s & Relatario do Sustorrebildadn - GEE \\
\hline & & & & Geraçio de residuos pelos usuarios & 1 & N & A & E.C & A & 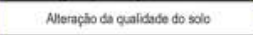 & 3 & 5 & 5 & is & 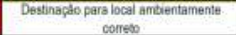 \\
\hline & & & & Gerachas do residuos do prescas & 1 & A & A & c & A & Alleragho do qualithide do solo & 3 & 5 & 3 & N & 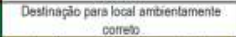 \\
\hline & & & & 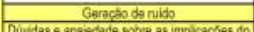 & $I$ & $\mathrm{~N}$ & A & $c$ & A & Amrerajo do ambientes sconcro & 3 & 3 & 3 & N & Menitoramento das rives de ruido \\
\hline & & & & 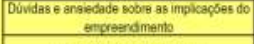 & 1 & N & $F$ & $s$ & $A$ & 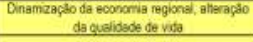 & 3 & 5 & 3 & N & Relustrio de Oundorit \\
\hline & & & & Afropelamento do antrais & 1 & A & A & c & A & Mheraplo da biofverndade (ffuna) & 5 & 1 & 1 & N & 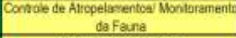 \\
\hline \multirow{11}{*}{ 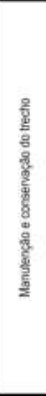 } & & \multirow{5}{*}{ 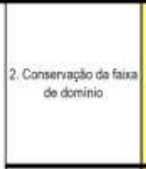 } & & 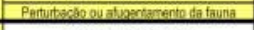 & $\perp$ & $\mathrm{N}$ & $p$ & $\mathrm{c}$ & A & 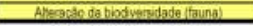 & 3 & 3 & 5 & N & Mondoramentinda Fauna \\
\hline & \multirow{10}{*}{ 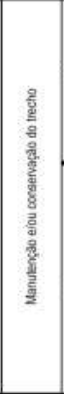 } & & \multirow{4}{*}{ 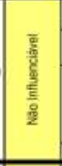 } & Supressio de vegetarjo & 1 & $\mathrm{~N}$ & A & $E, C$ & A & Allerapto da biodversidade & 5 & 3 & 5 & 4 & Seguir as condicionsctes de losenca \\
\hline & & & & Geragclo de residuos pelas usuarios & 1 & $\mathrm{~N}$ & A & $E, C$ & A & 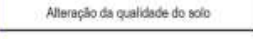 & 3 & 5 & 5 & 3 & 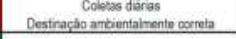 \\
\hline & & & & Geragafo de residivas pela comunistace & 1 & N & A & $E, C$ & A & Alleraç50 da qualidade do soilo & 3 & 5 & 3 & N & 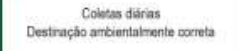 \\
\hline & & & & Usoecaubacdo do solo & 1 & $\mathrm{~N}$ & $A$ & $E, C$ & $\bar{A}$ & Allereraso da avalidade do scio & 5 & 3 & 5 & ב & 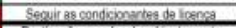 \\
\hline & & \multirow{6}{*}{ 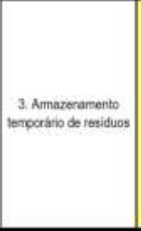 } & \multirow{6}{*}{ 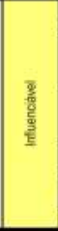 } & Armazenamento de resilous elettoeletronicos & 1 & N & A & $c$ & A & Aheraço da gualidade do scio & 5 & 5 & 3 & 3 & 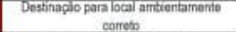 \\
\hline & & & & 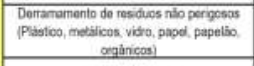 & 1 & N & A & $E, C$ & A & 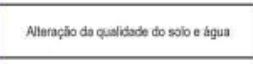 & 3 & 5 & 3 & N & 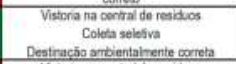 \\
\hline & & & & Geraçăo de medera & 1 & $\mathrm{~N}$ & A & $E, C$ & A & 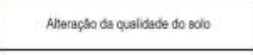 & s & 5 & 3 & 3 & 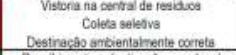 \\
\hline & & & & 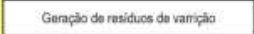 & 1 & N & A & E,C & A & Alatachabo de qualisade do scio & 3 & 1 & 3 & N & 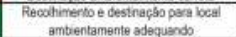 \\
\hline & & & & 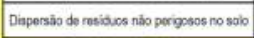 & 1 & A & A & $E, C$ & A & 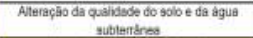 & 3 & 1 & 3 & N & 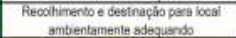 \\
\hline & & & & Destrascha de Residuos & $\mathrm{D}$ & $\mathrm{N}$ & A & $c$ & $\mathrm{~B}$ & Aheracso da ca lichade do solo & 3 & 5 & 1 & $\mathbb{N}$ & Sisterra MTR Onine \\
\hline
\end{tabular}

Fonte: Autor, 2018. 
A Matriz passa a ter um total de 24 (vinte e quatro) aspectos identificados, sendo 10 (dez) destes classificados como significativos. Os dados que foram inseridos ou alterados estão destacados na Matriz e serão discutidos a seguir.

A organização não possui controle sob o ciclo de vida de nenhum dos produtos atrelados à "Utilização da rodovia pelos usuários (Atividade 1)". Um dos aspectos existentes para essa atividade foi reavaliado.

O impacto ambiental associado à "Geração de emissões atmosféricas" passa a ser significativo, pois é reconsiderada a abragência do aspecto. Tendo em vista que o setor de transportes é o maior responsável pela geração de poluentes lançados na atmosfera (EPE, 2017), a abrangência que era classificada como "regional", torna-se "global". Conforme Piva (2010), o dióxido de carbono $\left(\mathrm{CO}_{2}\right)$, principal gás do efeito estufa, é produzido pela queima de combustíveis fósseis, sendo o mais importante dos poluentes responsáveis pelo aquecimento global. $\mathrm{O}$ autor ainda enfatiza que, segundo especialistas, se quisermos evitar níveis perigosos de aquecimento global, temos de cortar as emissões de $\mathrm{CO}_{2}$ de $80 \%$ a $90 \%$ até 2050.

Este aspecto não possuía um controle operacional existente, então foi definido o Relatório de Sustentabilidade - GEE (Gases de Efeito Estufa) ou GHG (greenhouse gases) como forma de monitoramento. Este relatório apresenta o inventário de GEE da Triunfo Participações e Investimentos S/A, referente às suas operações durante o ano, elaborado a partir dos conceitos e diretrizes estabelecidos pelas especificações de contabilização e quantificação do Programa Brasileiro GHG Protocol e em conformidade com a ISO 14064-1, Norma que orienta as organizações para quantificação e elaboração de relatórios de emissões e remoções de gases de efeito estufa. Surge aqui uma oportunidade de melhoria, sendo possível a implantação de um programa de incentivo a combustíveis renováveis, com o propósito de impulsionar o uso de veículos híbridos e elétricos.

Foram inseridos 4 novos aspectos ambientais que não eram considerados nesta atividade, descritos abaixo:

A "Geração de ruído" pode causar alteração no ambiente sonoro, consequentemente, pode gerar desconforto e inconveniência para a circunvizinhança. Os ruídos causados pelo tráfego de veículos podem variar a pressão sonora com o tipo 
de revestimento do asfalto e o tipo de veículo. Através de medições de ruídos em rodovias, são encontrados valores de 79 a 84 decibéis (dB) (SPECHT et al., 2007). Com ruídos acima de $70 \mathrm{~dB}$, o organismo fica sujeito a estresse degenerativo, além de poder abalar a saúde mental (CALIXTO E RODRIGUES, 2004 apud ZILIO, 2012). O monitoramento dos níveis de ruído é o controle operacional existente para este aspecto, havendo a oportunidade de implantar um programa de controle de ruídos.

“Dúvidas e ansiedade sobre a implicação do empreendimento" podem causar a dinamização da economia regional e alteração da qualidade de vida, pois este empreendimento refere-se a uma das principais rodovias do estado do Rio Grande do Sul, com uma área de concessão correspondente a $3.928 \mathrm{~km}^{2}$, onde vivem, aproximadamente, 2 milhões de habitantes (IBGE, 2010). Tendo em vista a influência do empreendimento, é importante a inserção deste aspecto. Como controle operacional, relacionado à "Comunicação Externa", item 7.4.3 da ABNT NBR ISO 14001:2015, as possíveis reclamações sobre o empreendimento poderão ser monitoradas pela ouvidoria, através de formulário disponível no site, via telefone, ou ainda pessoalmente na sede da empresa.

Sanchéz (2003), apud Gallardo (2004), considera os principais efeitos e impactos induzidos por um empreendimento rodoviário. Através de suas considerações para a fase de operação de uma rodovia, foram inseridos dois aspectos relacionados à fauna: "Atropelamento de animais" e "Perturbação ou afugentamento da fauna". Ambos aspectos podem provocar alteração na biodiversidade, causando impactos na fauna. Como controle operacional, por meio da contratação de consultoria ou parcerias com Instituições de Ensino, poderá ser realizado o controle dos atropelamentos e o monitoramento da fauna.

Com relação à "Conservação da faixa de domínio (Atividade 2)", a organização não possui controle sob o ciclo de vida de nenhum dos produtos atrelados à essa atividade. Para o aspecto de supressão vegetal, há a oportunidade de implantar um projeto de reposição florestal. Os demais aspectos já existentes foram mantidos.

A organização possui controle da disposição final dos produtos atrelados ao "Armazenamento temporário de resíduos (Atividade 3)" e, por isso, o controle do ciclo de vida é classificado como influencíavel. Para esta atividade, foi inserido um novo 
aspecto ambiental, a "Destinação de resíduos". Até então, este era citado apenas como controle operacional de outros aspectos. Neste levantamento, foi o único classificado como benéfico. O controle operacional é realizado através do Sistema de Manifesto de Transporte de Resíduos - MTR ONLINE, instituído pela Portaria FEPAM n⿳亠 033 (FEPAM, 2018). O destinador final emite um certificado no Sistema Online, atestando a tecnologia aplicada aos resíduos sólidos recebidos.

De modo geral, a maioria dos aspectos foram classificados como adversos, com impactos decorrentes de atividades de terceiros. Percebe-se que as atividades selecionadas relacionam-se entre si, uma exercendo influência à outra, pois são procedimentos e práticas vinculados à operação de uma rodovia.

Entre os novos critérios, a significância cultural deve ser ressaltada, pois este acaba se tornando uma outra forma de adotar a perspectiva do ciclo de vida, sendo uma das mudanças mais relevantes trazidas por esta edição da Norma. Para determinar a significância cultural, é preciso ter uma visão geral das implicações do empreendimento, não somente na fase de operação, e sim no ciclo de vida da rodovia como um todo.

Concluída a etapa da identificação dos aspectos ambientais, a Norma estabele que é necessário fazer a abordagem dos riscos e oportunidades e, para isso, além do que já foi identificado nessa discussão, recomenda-se a adoção de uma metodologia mais focada nesse ponto, levando em conta a determinação destes aspectos juntamente com os requisitos legais, de forma a possibilitar o desenvolvimento dos planos de ação.

\section{CONCLUSÃO}

A temática da gestão ambiental e da conservação ambiental não tende a ser um fato passageiro ou um modismo empresarial, tendo em vista o objetivo da Norma ABNT NBR ISO 14001:2015, que pretende fornecer de forma estável o conjunto de requisitos aqui apresentados para, pelo menos, os próximos 10 (dez) anos.

A tendência de preservação ambiental e ecológica por parte das organizações deve continuar de forma permanente e definitiva. A gestão ambiental tornou-se e 
deverá tornar-se, em ritmo crescente, importante instrumento de gerenciamento no sentido de tornar as empresas competitivas.

A implementação de um Sistema de Gestão é imprescindível para todas as organizações, visto que não é possível administrar sem organizar, sem pensar e refletir. Nesse segmento, a Norma torna possível a implantação de um Sistema de Gestão Ambiental consistente para alcançar os objetivos ambientais.

Embora a edição de 2015 esteja trazendo alguns novos requisitos que só a leitura minuciosa da Norma permitirá identificar totalmente, pode-se concluir que muitas das alterações resumiram-se apenas em tornar claras diversas práticas que as organizações já aplicavam.

Entre os desafios da atualização, a inserção da perspectiva do ciclo de vida no ramo da organização aqui estudada é um ponto a ser considerado, pois há uma maior facilidade em aplicar esta perspectiva quando se trata de um processo produtivo. Porém, tratando-se de um serviço, demanda maior amadurecimento por parte da organização, pois torna-se um critério bastante subjetivo.

O trabalho trouxe uma maior compreensão acerca dos sistemas de gestão ambiental, especialmente para a fase de planejamento, base inicial na busca dos resultados pretendidos pelo sistema. É através desta etapa que será possível mapear os impactos causados pela empresa e agir para a redução destes.

Por fim, almeja-se que os resultados alcançados neste trabalho sirvam de apoio para que empresas do ramo implementem seus respectivos Sistemas de Gestão Ambiental, baseados na versão 2015 da ABNT NBR ISO 14001.

\section{Referências}

AGÊNCIA NACIONAL DE TRANSPORTES TERRESTRES (ANTT). Programa de Exploração da Rodovia - PER. Rodovia BR-290/RS Trecho: Osório - Guaíba. Documento. Brasília, 2015. Disponível em: <http://www.antt.gov.br/backend/galeria/arquivos/PER_atualizado_Concepa.pdf >. Acesso em: 18 mar 2018.

\section{ALBERTON, A. Meio Ambiente e desempenho econômico-financeiro: Impacto da ISO 14001 nas Empresas Brasileiras. 2003. 285p. Tese - Doutorado -}


Engenharia de Produção e Sistemas, Universidade Federal de Santa Catarina, Florianópolis, 2003.

ASSOCIAÇÃO BRASILEIRA DE NORMAS TÉCNICAS (ABNT) NBR 14001: Sistemas de Gestão Ambiental - Requisitos com orientação para uso. Norma ABNT. Rio de Janeiro, 2004a. Disponível em: $<$ http://www.madeira.ufpr.br/disciplinasghislaine/iso-14001-2004.pdf>. Acesso em: 2 mar 2018.

ASSOCIAÇÃO BRASILEIRA DE NORMAS TÉCNICAS (ABNT) NBR 10004: Resíduos Sólidos - Classificação. Norma ABNT. Rio de Janeiro. 2004b. Disponível em: $<$ http://www.suape.pe.gov.br/images/publicacoes/normas/ABNT_NBR_n_10004_ 2004.pdf>. Acesso em: 4 abr 2018.

ASSOCIAÇÃO BRASILEIRA DE NORMAS TÉCNICAS (ABNT). NBR 14001: Sistemas de Gestão Ambiental - Requisitos com orientação para uso. Norma ABNT. Rio de Janeiro, 2015. Disponível em: <https://www.iso.org/obp/ui/\#iso:std:iso:14001:ed-3:v1 :en>. Acesso em: 2 mar 2018.

ASSOCIAÇÃO PORTUGUESA DE CERTIFICAÇÃO (APCER). Guia do Utilizador ISO 14001:2015. Apostila APCER. Portugal, 2016. Disponível em:

$<$ https://www.apcergroup.com/portugal/images/site/graphics/guias/apcer_guia_is 014001.pdf>. Acesso em: 25 mar 2018.

BLACKESTAM, A., \& OLOFSSON, A. Environmental certification - why do companies seek it? A comparative case study of ISO 14001 certified companies in Umeå, 2013. 111p. Artigo - Umeå School of Business and Economics. Umeå, 2013.

BRASIL. Conselho Nacional de Meio Ambiente (CONAMA). Resolução CONAMA №. 001 de 23 de janeiro de 1986. Brasília. Disponível em:

<http://www.mma.gov.br/port/conama/res/res86/res0186.html>. Acesso em: 6 abr 2018.

BRIGGS, S. L. ISO 14001:2015 - Key Changes. TC 207 - Apresentação em Workshop . Nova Delhi, 2015. Disponível em: <https://committee.iso.org/files/live/sites/tc207sc1/files/TC207\%20SC1\%20ISO\% $2014001 \% 20$ workshop\%20on\%20changes\%208\%20Sept\%202015\%20slides.pd f>. Acesso em: 19 mar 2018.

BRITISH STANDARDS INSTITUTION (BSI). Moving from ISO 14001:2004 to ISO 14001:2015. Apostila - BSI Training. Londres, 2015. Disponível em: $<$ https://www.bsigroup.com/LocalFiles/en-GB/iso-14001/Revisions/ISO-14001transition-guide-July-2015-FINAL.pdf>. Acesso em: 15 abr 2018. 
BRUNDTLAND, G. H. Report of the World Comission on environment and development: "Our common future". Relatório - Organização das Nações Unidas (ONU), 1987. Disponível em: <http://www.un-documents.net/ourcommon-future.pdf>. Acesso em: 11 mar 2018.

BUREAU VERITAS QUALITY INTERNATIONAL (BVQI). Top management environmental managers technical guide. Apostila- BVQI. Paris, 2015.

CONCESSIONÁRIA DA RODOVIA OSÓRIO - PORTO ALEGRE S.A (CONCEPA). Manual do Sistema de Gestão Integrada. Documento Interno - Triunfo Concepa. Rio Grande do Sul, 2018a.

CONCESSIONÁRIA DA RODOVIA OSÓRIO - PORTO ALEGRE S.A (CONCEPA). Certificados do Sistema de Gestão Integrada. Documento Interno - Triunfo Concepa. Rio Grande do Sul, 2018b.

CONCESSIONÁRIA DA RODOVIA OSÓRIO - PORTO ALEGRE S.A (CONCEPA). Política do Sistema de Gestão. Documento Interno - Triunfo Concepa. Rio Grande do Sul, 2018c.

CONCESSIONÁRIA DA RODOVIA OSÓRIO - PORTO ALEGRE S.A (CONCEPA). Registro de Qualidade 200-04. Documento Interno - Triunfo Concepa. Rio Grande do Sul, 2018d.

DA SILVA, L. C., \& DE MELO, D. D. O processo de avaliação de aspectos e impactos ambientais em um Sistema de Gestão Ambiental com referência na ISO 14001. Revista DELOS: Desarrollo Local Sostenible. 2017. Disponível em: <http://www.eumed.net/rev/delos/28/ISO14001.html>. Acesso em: 2 mai 2018.

EMPRESA DE PESQUISA ENERGÉTICA (EPE). Balanço Energético Nacional 2017: ano base 2016. Relatório - EPE. Rio de Janeiro, 2017. Disponível em: $<$ https://ben.epe.gov.br/downloads/Relatorio_Final_BEN_2017.pdf>. Acesso em: 29 mai 2018.

ENGUITA, M. F. A face oculta da escola: educação e trabalho no capitalismo. Editora Artes Médicas do Sul. Porto Alegre, 1989.

FUNDAÇÃO ESTADUAL DE PROTEÇÃO AMBIENTAL HENRIQUE LUIZ ROESSLER (FEPAM). Licença de Operação №. 2056/2014-DL. Operação de Trecho da Rodovia BR-290 "Freeway" Segmento de Osório à Eldorado do Sul. Documento - FEPAM. Rio Grande do Sul, 2014. Disponível em: <http://ww2.fepam.rs.gov.br/doclics/signed/2016/754874_signed.pdf>. Acesso em: 22 mar 2018 (FEPAM). Portaria FEPAM № 33 DE 23/04/2018: Aprova o Sistema de 
Manifesto de Transporte de Resíduos - Sistema MTR Online e dispõe sobre a obrigatoriedade de utilização do Sistema no Estado do Rio Grande do Sul e dá outras providências. Documento - FEPAM. Porto Alegre, 2018. Disponível em: <https://www.legisweb.com.br/legislacao/?id=359329>. Acesso em: 22 mar 2018.

GALLARDO, A. L. C. F. Análise das práticas de gestão ambiental da construção da pista descendente da Rodovia dos Imigrantes. 295p, Tese - Doutorado em Engenharia. Escola Politécnica- Universidade de São Paulo. São Paulo, 2004.

INSTITUTO BRASILEIRO DE GEOGRAFIA E ESTATÍSTICA (IBGE). Censo Demográfico 2010. Documento - Biblioteca IBGE. Rio de Janeiro, 2010. Disponível em: <https://biblioteca.ibge.gov.br/pt/bibliotecacatalogo?view=detalhes\&id=7552>. Acesso em: 29 mai 2018.

INTERNATIONAL ORGANIZATION FOR STANDARDIZATION (ISO). TC 207/SC 1 Why was ISO 14001 revised. Publicação em site, 2018. Disponível em: <https://committee.iso.org/sites/tc207sc1/home/projects/published/iso-14001--environmental-manage/why-was-the-standard-revised.html>. Acesso em: 20 mar 2018.

INTERNATIONAL ORGANIZATION FOR STANDARDIZATION (ISO). The ISO Survey of Management System Standard Certifications 2016. Relatório - ISO, 2016a.

INTERNATIONAL ORGANIZATION FOR STANDARDIZATION (ISO). 14004:2016 Environmental management systems- General guidelines on principles, systems and supporting. Norma - ISO, 2016b.

NAHUZ, M. A. O Sistema ISO 14000 e a certificação ambiental. Revista de Administração de Empresas (RAE), vol.35, n.6, p.55-66. 1995. Disponível em: <http://www.scielo.br/pdf/rae/v35n6/a07v35n6.pdf>. Acesso em: 13 mar 2018.

NETO, A. S., DE SOUZA CAMPOS, L. M., \& SHIGUNOV, T. Fundamentos da Gestão Ambiental. Editora Ciência Moderna. Rio de Janeiro, 2009.

OLIVEIRA, O. J., \& PINHEIRO, C. R. Implantação de sistemas de gestão ambiental ISO 14001: uma contribuição da área de gestão de pessoas. Revista Gestão \& Produção, vol.17, n.1, p.51-6. São Carlos, 2010. Disponível em: <http://www.scielo.br/pdf/gp/v17n1/v17n1a05.pdf>. Acesso em: 20 mar 2018.

PARK, K. Quantitative assessment of environmental impacts on life cycle of highways. Journal of construction engineering and management, v. 129, n.1, p 25-31. 2003.

PIVA, R. B. Economia ambiental sustentável: os combustíveis fósseis e as alternativas energéticas. Trabalho de Conclusão de Curso (Bacharel em Ciências Econômicas) - Universidade Federal do Rio Grande do Sul. Porto 
Alegre, 2010. Disponível em: <http://hdl.handle.net/10183/26107>. Acesso em: 21 mai 2018.

ROMAN, M. Avaliação de impactos ambientais de rodovias: análise de projetos de ampliação da capacidade rodoviária e proposição de diretrizes para o licenciamento ambiental. Mestrado, Universidade Federal do Rio Grande do Sul. Instituto de Geociências. Programa de Pós-Graduação em Geografia. Porto Alegre, 2016. Disponível em: <http://hdl.handle.net/10183/151321>. Acesso em: 22 mar 2018.

SEIFFERT, M. E. Gestão Ambiental: instrumentos, esferas de ação e educação ambiental. Editora Atlas. São Paulo, 2010.

SEIFFERT, M. E. ISO 14001 Sistemas de Gestão Ambiental - Implantação objetiva e econômica. Editora Atlas. São Paulo, 2006.

SPECHT, L. P., KOHLER, R., KHATCHATOURIAN, O. A., CALLAI, S. C., \& CERATTI, J. A. Avaliação do ruído causado pelo tráfego de veículos em diferentes rodovias. In: Anais do XXI Congresso de Pesquisa e Ensino em Transportes. Rio de Janeiro, 2007.

STICHTING COORDINATE CERTIFICATIE MILIEU (SCCM). Making the transition to ISO 14001:2015. Apostila SCCM. Den Haag, 2016. Disponível em: $<$ https://www.sccm.nl/sites/default/files/BM20SCCM_N150506_Transition_to_ISO_14001-2015_EN_16Jun16.pdf>

TSUNOKAWA, K., \& HOBAN, C. Roads and the environment: a handbook. World Bank Technical Paper. Washington, 1997.

TÜV SÜD America Inc. Navigating ISO 14001:2015. Alemanha, 2015. Disponível em: $<$ http://www.tuv-sudamerica.com/uploads/images/1418760108384850270824/iso140012015whitepaper-us-final.pdf>. Acesso em: 16 mar 2018.

ZILIO, J. L. Estudo das condições acústicas em praças de alimentação de shopping centers na cidade de Porto Alegre. Especialização. Universidade Federal do Rio Grande do Sul. Escola de Engenharia. Engenharia de Segurança do Trabalho. Porto Alegre, 2012.Disponível em: <http://hdl.handle.net/10183/98109>. Acesso em: 13 mai 2018. 